\title{
Plastic Response of Medicago sativa L. root system traits and cold resistance to simulated rainfall events
}

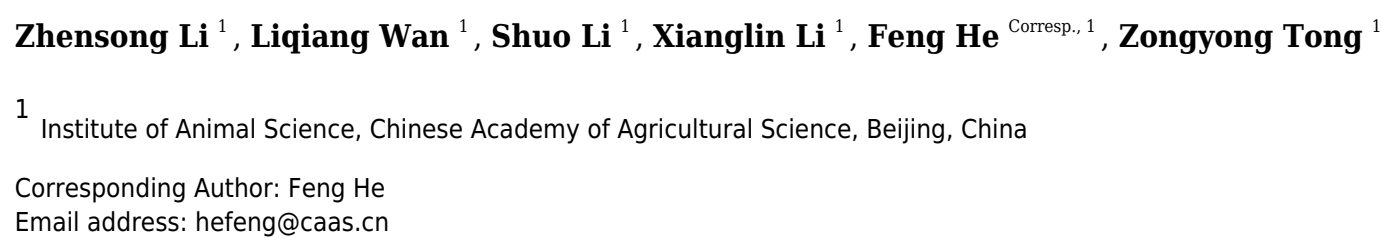

Climate change (rainfall events and global warming) affects the survival of alfalfa (Medicago sativa L.) in winter. Appropriate water management can quickly reduce the mortality of alfalfa during winter. To determine how changes in water affect the cold resistance of alfalfa, we explored the root system traits under different rainfall events and the effects on cold resistance in three alfalfa cultivars. These were exposed to three simulated rainfall events $(S R E) \times$ two phases in a randomized complete block design with six replications. The three cultivars were WL168, WL353 and WL440, and the three SRE were irrigation once every second day $\left(D_{2}\right)$, every four days $\left(D_{4}\right)$ and every eight days $\left(D_{8}\right)$. There were two phases: before cold acclimation and after cold acclimation. Our results demonstrated that a period of exposure to low temperature was required for alfalfa to achieve maximum cold resistance. The root system tended toward herringbone branching under $D_{8}$, compared with $D_{2}$ and $D_{4}$, and demonstrated greater root biomass, crown diameter, root volume, average link length and topological index. Nevertheless, $D_{8}$ had less lateral root length, root surface area, specific root length, root forks and fractal dimensions. Greater root biomass and topological index were beneficial to cold resistance in alfalfa, while more lateral roots and root forks inhibited its ability to survive winter. Alfalfa roots had higher proline, soluble sugar and starch content in $D_{8}$ than in $D_{2}$ and $D_{4}$. In contrast, there was lower malondialdehyde in $\mathrm{D}_{8}$, indicating that alfalfa had better cold resistance following a longer irrigation interval before winter. After examining root biomass, root system traits and physiological indexes we concluded that WL168 exhibited stronger cold resistance. Our results contribute to greater understanding of root and cold stress and, consequently, provide references for selection of cultivars and field water management to improve cold resistance of alfalfa in the context of changes in rainfall patterns. 
1 Plastic Response of Medicago sativa $\mathrm{L}$. root system traits and cold resistance to 2 simulated rainfall events

3

8 Corresponding Author:

9 Feng He,

\section{Abstract}

\section{Introduction}

Zhensong Li, Liqiang Wan, Shuo Li, Xianglin Li, Feng He, Zongyong Tong

Institute of Animal Science, Chinese Academy of Agricultural Science, Beijing, China

No.2, Yuanmingyuan West Road, Haidian District, Beijing, 100193, China

Email address: hefeng@caas.cn

Climate change (rainfall events and global warming) affects the survival of alfalfa (Medicago sativa L.) in winter. Appropriate water management can quickly reduce the mortality of alfalfa during winter. To determine how changes in water affect the cold resistance of alfalfa, we explored the root system traits under different rainfall events and the effects on cold resistance in three alfalfa cultivars. These were exposed to three simulated rainfall events (SRE) $\times$ two phases in a randomized complete block design with six replications. The three cultivars were WL168, WL353 and WL440, and the three SRE were irrigation once every second day $\left(\mathrm{D}_{2}\right)$, every four days $\left(D_{4}\right)$ and every eight days $\left(D_{8}\right)$. There were two phases: before cold acclimation and after cold acclimation. Our results demonstrated that a period of exposure to low temperature was required for alfalfa to achieve maximum cold resistance. The root system tended toward herringbone branching under $\mathrm{D}_{8}$, compared with $\mathrm{D}_{2}$ and $\mathrm{D}_{4}$, and demonstrated greater root biomass, crown diameter, root volume, average link length and topological index. Nevertheless, $\mathrm{D}_{8}$ had less lateral root length, root surface area, specific root length, root forks and fractal dimensions. Greater root biomass and topological index were beneficial to cold resistance in alfalfa, while more lateral roots and root forks inhibited its ability to survive winter. Alfalfa roots had higher proline, soluble sugar and starch content in $\mathrm{D}_{8}$ than in $\mathrm{D}_{2}$ and $\mathrm{D}_{4}$. In contrast, there was lower malondialdehyde in $\mathrm{D}_{8}$, indicating that alfalfa had better cold resistance following a longer irrigation interval before winter. After examining root biomass, root system traits and physiological indexes we concluded that WL168 exhibited stronger cold resistance. Our results contribute to greater understanding of root and cold stress and, consequently, provide references for selection of cultivars and field water management to improve cold resistance of alfalfa in the context of changes in rainfall patterns.

Alfalfa (Medicago sativa L.) has spread widely because of its productivity and palatability. The global area planted with alfalfa is about $3.2 \times 10^{7} \mathrm{hm}^{2}$ and is mainly distributed in the United 
40 States, Russia and Argentina (Russelle, 2001). The area planted with alfalfa exceeds $4 \times 10^{6} \mathrm{hm}^{2}$ 41 in China (He, 2011), where it is mainly distributed in the high latitudes. There has been frequent

42

43

44

45

46

47

48

49

50

51

52

53

54

55

56

57

58

59

60

61

62

63

64

65

66

67

68

69

70

71

72

73

74

75

76

77

78

79 crop failure due to winter conditions in recent years, such as the "Easter freeze" of 2007 in the United States (Augspurger, 2009) and the frost in northern China from 2012 to 2020 (Yang, 2019). The failure of alfalfa to overwinter not only causes huge economic losses (Castonguay, 2006), but also reduces biological nitrogen fixation and increases nitrous oxide emissions from agronomic ecosystems, leading to an increased risk of global warming (Crews \& Peoples, 2004; Robertson, 2000). The IPCC Fifth Assessment Report showed that the average temperature of the world had risen by $0.85^{\circ} \mathrm{C}$ in the past 100 years and by $1{ }^{\circ} \mathrm{C}$ in China over the past few decades (Fang, 2018). Two major factors linked to climate change are likely to affect plant winter survival: changes in precipitation and temperatures (Be'langer, 2002; CCAF, 2001). Extreme low temperature is more likely to reduce the survival rate of alfalfa in winter owing to reduced snowfall, and greater temperature fluctuation can make alfalfa break dormancy prematurely, exposing vulnerable buds to subsequent killing frost and causing sustained damage (Augspurger, 2009). Modeling of global climate change has predicted that alfalfa death due to reduced snowfall and greater temperature fluctuation will occur more frequently in the future (Carol, 2013; Ji, 2017).

Alfalfa needs to undergo a period of low temperature and a short photoperiod to obtain its freezing tolerance, and this is known as cold acclimation (Theocharis, 2012; Trischuk, 2014). Appropriate cultivation measures are also an effective way to improve cold resistance. Water plays an important role in the winter hardiness of alfalfa because freezing injury is mainly caused by cell dehydration (Xu, 2020a; Xu, 2020b; Zhang, 2015). Water can not only affect the cold resistance of alfalfa by changing the morphology and spatial distribution of the root system, but also protect cells from low-temperature damage through physiological metabolic pathways (Castonguay et al., 2006). In addition to precipitation amount, the impact on root growth also includes precipitation timing and interval. Research has shown that precipitation events have different effects on various plants, and high-frequency light precipitation events were found to have a greater impact on herbaceous plants (Schwinning \& Sala, 2004;

Schwinning, 2003). The root system is key to the ability of alfalfa to resist low temperature. Plants can regulate root system development in response to dynamic changes in soil moisture (Comas, 2013; $\mathrm{Li}$, 2020). Previous studies have documented that below-ground biomass (BGB) (Larson \& Smith, 1963; Liu, 2015), root crown (Larson \& Smith, 1963; Liu et al., 2015; Schwab, 1996), lateral roots (Liu et al., 2015; Smith, 1951) and root system spatial distribution (Castonguay et al., 2006) all affect the cold resistance of alfalfa. According to the cross acclimation theory (Kong \& Henry, 2019a; 2019b), low-frequency heavy precipitation will increase the time plants spend in drought conditions, and so improve the cold resistance of alfalfa. This is because drought can enhance the antioxidant capacity and osmotic regulation of plants, including changes in malondialdehyde (MDA) (Schwab et al., 1996), proline (Pro) (Janska, 2010), soluble sugars (SS) (Trischuk et al., 2014) and starch content (Xu et al., 2020a), and these are closely related to the cold resistance of alfalfa. MDA reflects the degree of membrane lipid 
80 peroxidation in the cell membrane, and its content is directly proportional to the low temperature

81 injury of alfalfa (Schwab et al., 1996). Proline improves the cold resistance of plants by

82 regulating osmotic balance and increasing protein solubility (Janska, 2010). Soluble sugar acts as

83 osmotic regulator, cryoprotectant, and signaling molecule to stabilize the cell membrane and

84 scavenge reactive oxygen species under low temperature (Trischuk et al., 2014). Starch can be

85 broken down into soluble sugar to improve the cold resistance of alfalfa (Xu et al., 2020a).

86 Our experiment simulated the effects of different precipitation patterns on alfalfa root traits and

87 cold resistance. The purpose was to: (1) study the response of root morphology and spatial

88 distribution to different precipitation events; (2) clarify the relationship between root traits and

89 cold resistance; (3) explain the effect of different precipitation patterns on cold resistance; (4)

90 clarify whether precipitation patterns have differences in the root traits of alfalfa cultivars. These

91 are of great significance since the water management could prove important for increasing cold

92 resistance.

93

94 Materials \& Methods

95 Experiment Location and Materials

96 This experiment was conducted in a controlled greenhouse at the Institute of Animal Science,

97 Chinese Academy of Agricultural Sciences (Beijing, China) from May to September 2020, with

$9825^{\circ} \mathrm{C} / 20^{\circ} \mathrm{C}$ (day/night), $14 \mathrm{~h} / 10 \mathrm{~h}$ (light/dark) and photosynthetic photon flux density of 350

$99 \mu \mathrm{mol} \cdot \mathrm{m}^{-2} \cdot \mathrm{s}^{-1}$ at $60 \%-65 \%$ relative humidity. Alfalfa seeds were disinfected with sodium

100 hypochlorite $(1 \% \mathrm{NaClO})$ for 30 min and washed with deionized water five times. We then

101 selected seeds of the same size and germinated them in a Petri dish with $14 \mathrm{~h}$ light and $10 \mathrm{~h}$ dark

102 at $25^{\circ} \mathrm{C}$. After $72 \mathrm{~h}$ we moved three germinant seeds into one polyvinyl chloride (PVC) pipe with

103 an inner diameter of $18 \mathrm{~cm}$ and height of $50 \mathrm{~cm}$. A nylon mesh bag was placed in each pipe (to

104 facilitate later sampling) and this was filled with $2.5 \mathrm{~kg}$ of sterilized dry mixture with a volume

105 ratio of 4:1 sandy soil and nutrient soil mixture. The nutrient soil mixture is a cultivation medium

106 (composed of peat moss and lime), named TS1, produced by Klasmann-Deilmann. TS1 contains

$1071.6 \%$ total nitrogen, $0.1 \% \mathrm{P} 2 \mathrm{O} 5,0.2 \% \mathrm{~K} 2 \mathrm{O}(\mathrm{N}: \mathrm{P}: \mathrm{K}=14: 10: 18)$ and $91 \%$ of organic matter,

108 with a conductivity of $0.9 \mathrm{dS} / \mathrm{m}$ and $\mathrm{pH}$ of 5.8. The water-holding capacity (WHC) of the

109 mixture was measured to be $38.35 \%$. One plant was left in each PVC pipe 1 week after

110 transplanting according to its height (about $15 \mathrm{~cm}$ ), and cultivation continued for another 2

111 weeks before subsequent experimentation. The soil moisture content was kept at $60 \%-65 \%$

112 WHC by weighing the pipe every second day. Weeds and pests were removed regularly.

\section{Experiment Designs and Treatments}

114 A randomized complete block design was used, with three alfalfa cultivars (C), three simulated

115 rainfall events (SRE) and two phases. The three alfalfa C were WL168, WL353 and WL440

Peer) reviewing PDF | (2021:03:59266:2:1:NEW 15 Jul 2021) 
116 (with a fall dormancy score of 2, 4 and 6, respectively; provided by Beijing Zhengdao Seed

117 Industry Co., Ltd.). These are commonly planted in large areas of northern China and represent

118 the range in fall dormancy scores of alfalfa $\mathrm{C}$ grown in the region. The three SRE were:

119 irrigation once every second day $\left(D_{2}\right)$, every four days $\left(D_{4}\right)$ and every eight days $\left(D_{8}\right) . D_{2}$

120 represented a high-frequency light precipitation and $\mathrm{D}_{8}$ represented a low-frequency heavy

121 precipitation. The two phases were phase 1 (before cold acclimation) and phase 2 (after cold

122 acclimation). The combined $3 \times 3 \times 2 \times 6$ repetitions $=108 \mathrm{PVC}$ pipes.

123 According to the preliminary test, the soil moisture content of $\mathrm{D}_{2}, \mathrm{D}_{4}$ and $\mathrm{D}_{8}$ before the next

124 irrigation was about 50\%, 40\% and 30\% of WHC respectively. We carried out three irrigation

125 interval treatments, and total irrigation quotas remained the same between different treatments

126 and determined by $\mathrm{D}_{2}$ (keeping the soil moisture content at $60 \%-65 \%$ of the WHC by weighing

127 every second day). After 8 weeks we carried out phase 1 sampling $(3 \times 3 \times 6=54$ pipes in total,

128 as shown in Fig.1). The aboveground and underground parts were separated and then carefully

129 removed from the nylon mesh bag in each PVC pipe to minimize damage to the spatial

130 distribution of the root system. The root surface mixture was washed away gently with distilled

131 water by hand and the roots were placed evenly in a transparent acrylic tray with $1200 \mathrm{~mL}$ of

132 distilled water. They were then scanned with a MICROTEK Scan Maker i800plus (Microtek

133 Technology Co., Ltd., Shanghai, China) with a resolution of 600 dpi. Immediately after scanning,

134 about $5 \mathrm{~cm}$ of the root crown was used to determine electrical conductivity and physiological

135 indicators. We divided the sample into two parts, one part was used for the determination of $\mathrm{LT}_{50}$,

136 the other part was used for the determination of physiological indicators. The remainder of the

137 root was measured to calculate biomass. The aboveground and underground parts were weighed

138 after being placed in an oven at $65^{\circ} \mathrm{C}$ for $48 \mathrm{~h}$ and the dry weight were above-ground biomass

139 (AGB) and below-ground biomass (BGB).

140 The rest half of the experimental plants were moved to an LRH-200-GD low-temperature light

141 incubator (Taihong Medical Instruments, Guangdong, China) for the low-temperature

142 experiment (phase 2). The initial temperature was $25^{\circ} \mathrm{C} / 20^{\circ} \mathrm{C}$ (day/night) with a photoperiod of

$14310 \mathrm{~h}$ light and $14 \mathrm{~h}$ dark, and the photosynthetic photon flux density was $350 \mu \mathrm{mol} \cdot \mathrm{m}^{-2} \cdot \mathrm{s}^{-1}$. The

144 temperature was decreased to $5^{\circ} \mathrm{C} / 0^{\circ} \mathrm{C}$ (day/night) at a rate of $2^{\circ} \mathrm{C} \cdot \mathrm{d}^{-1}$ and the light intensity was

145 decreased to $150 \mu \mathrm{mol} \cdot \mathrm{m}^{-2} \cdot \mathrm{s}^{-1}$ at a rate of $20 \mu \mathrm{mol} \cdot \mathrm{m}^{-2} \cdot \mathrm{s}^{-1} \cdot \mathrm{d}^{-1}$, simulating the cold adaptation

146 environment of alfalfa. Sampling was carried out after a further $72 \mathrm{~h}$ of cold acclimation. During

147 this phase of the experiment, plants were watered as in the previous phase. The root was

148 carefully rinsed by hand with distilled water after the test and the root crown sample was divided

149 into two parts. One part was used for the measurement of electrical conductivity and the other for

150 physiological indicators (kept at $-80^{\circ} \mathrm{C}$ ).

Measurements 
152 Root Morphological Indicators

153 We used a Win-RHIZO 2017a (Regent Instruments, Inc., Quebec, QC, Canada) to analyze the 154 scanned images (Fig. 2). The process included thresholding, framing, editing breakpoints and

155 eliminating loops to obtain the root morphological indicators, root length, root surface area 156 (RSA), root volume (RV), root forks (RF) and average link length (ALL). Topological index (TI) 157 and fractal dimensions (FD) were obtained by calculation.

158 TI is used to reflect the spatial structure of different root systems and is defined as log altitude 159 (A)/log magnitude (M) where $\mathrm{A}$ is the number of links in the longest path from an exterior link 160 to the most basal link of the root system and $\mathrm{M}$ is the total number of the exterior links (Bouma,

161 2001). When TI is close to 0.5 , the root system tends to a dichotomous branching and when close 162 to 1 it tends to herringbone branching. FD were obtained according to the box-dimension 163 method (Bouma et al., 2001; Fitter, 1986; Fitter, 1991; Harrar \& Hamami, 2007).

\section{Semi-lethal Temperature}

165 The semi-lethal temperature $\left(\mathrm{LT}_{50}\right.$, the temperature at which the relative permeability of 166 intracellular ions attains 50\%) was used to represent the cold resistance of alfalfa in this

167

168

169

170

171

172

173

174

175

176

177

178

179

180

181

182

183

184

185 study (Anower, 2016). We took the $5 \mathrm{~cm}$ underground taproot as the root crown, and then we cut the root crown into 9 pieces of 2-3 mm (based on length instead of diameter), and these pieces were put into nine $2-\mathrm{mL}$ centrifuge tubes $(X u, 2020 \mathrm{a})$. Tubes were placed at $8^{\circ} \mathrm{C}$ for $2 \mathrm{~h}$. The subsequent freezing test was conducted in a ZX-5C constant-temperature circulator (Zhixin Instrument, Shanghai, China) under a decreasing series of nine temperatures, and tubes with samples were kept in alcohol for $1.5 \mathrm{~h}$ at each temperature. The temperatures of the alcohol were different due to the difference between the $\mathrm{LT}_{50}$ under the two treatments. For the samples collected in phase 1 , nine temperatures were set to $8,6,4,2,0,-2,-4,-6$ and $-8^{\circ} \mathrm{C}$. For the samples collected in phase 2 , nine temperatures were set to $0,-2,-4,-6,-8,-10,-12,-14$ and $-16^{\circ} \mathrm{C}$. After $1.5 \mathrm{~h}$ at the first temperature in each phase, one tube was transferred to storage at that temperature; after $1.5 \mathrm{~h}$ at the second temperature another tube was removed for storage at that temperature; and so on until all nine tubes in each phase were stored at their designated temperatures. We then removed the pieces of root crown from each $2-\mathrm{mL}$ tube and placed them in one $15-\mathrm{mL}$ tube and added $5 \mathrm{~mL}$ deionized water. This tube was shaken on an HZQ-A gyratory platform shaker (Hengrui Instrument and Equipment, Changzhou, China) at $120 \mathrm{rpm}$ for $12 \mathrm{~h}$ at $25^{\circ} \mathrm{C}$. Next used a conductivity meter FE38 (Mettler, Shanghai, China) to measure the electrical conductivity as $\mathrm{EL}_{1}$. The sample was autoclaved at $121^{\circ} \mathrm{C}$ for $30 \mathrm{~min}$ and, on remeasuring, its electrical conductivity was found to be $\mathrm{EL}_{2}$. The electrical conductivity of deionized water was EL. Relative electrolyte leakage can be calculated according to Eq. (1) and 
186 the semi-lethal temperature can be calculated by logistic Eq. (2). In Eq. (2), $\mathrm{x}$ is the freezing

187

188

189

190

191

192

193

194

195

196

197

198

199

200

201

202

203

204

205

206

207

208

209

210

211

213

215

217

$2125 \mathrm{~min}$. (4) Measured the absorbance of the supernatant at $520 \mathrm{~nm}$ and calculated the Pro content 214 standard curve, $\mathrm{V}_{1}(\mathrm{~mL})$ is the total volume of the extraction, $\mathrm{A}(\mathrm{mL})$ is the volume of the

216 Pro $(\mu \mathrm{g} / \mathrm{g} \mathrm{DW})=\left(\mathrm{C} \times \mathrm{V}_{1} / \mathrm{A}\right) / \mathrm{DW}$. temperature, $\mathrm{y}$ is the relative electrical leakage and $\mathrm{A}, \mathrm{B}$ and $\mathrm{k}$ are constants:

Relative electrolyte leakage $(\%)=\left(E_{1}-E L\right) /\left(E L_{2}-E L\right) \times 100$.

$\mathrm{y}=\mathrm{A} /\left(1+\mathrm{B} \times \mathrm{e}^{-\mathrm{kx}}\right) \times 100 \%$.

\section{Root Physiological Indexes}

Physiological indexes were also measured on root crown of alfalfa. Ground the other part of the crown sample kept at $-80^{\circ} \mathrm{C}$ into powder and then determined their SS (Buysse \& Merckx, 1993), starch (Buysse \& Merckx, 1993), MDA (Dhindsa, 1981) and Pro content (Bates, 1973).

Malondialdehyde (MDA)

A 0.2 -g sample was placed in a 10-ml test tube for determination of MDA. (1) Added $5 \mathrm{~mL} 0.1 \%$ cold trichloroacetic acid (TCA) and then the homogenate was centrifuged at $10000 \mathrm{r} / \mathrm{min}$ for 5 min at $4{ }^{\circ} \mathrm{C}$. (2) To $1 \mathrm{~mL}$ aliquot of the supernatant $4 \mathrm{~mL} 20 \%$ TCA containing $0.5 \%$ TBA were added. The mixture was heated at $95^{\circ} \mathrm{C}$ for $20 \mathrm{~min}$ and then quickly cooled in an ice-bath. After centrifuging at $4000 \mathrm{r} / \mathrm{min}$ for $15 \mathrm{~min}$, then $2 \mathrm{~mL}$ supernatant was removed to a cuvette and $2 \mathrm{~mL}$ deionized water used as control. (3) The absorbance of the supernatant was measured at $450 \mathrm{~nm}$ $\left(\mathrm{OD}_{450}\right), 532 \mathrm{~nm}\left(\mathrm{OD}_{532}\right)$ and $600 \mathrm{~nm}\left(\mathrm{OD}_{600}\right)$. The MDA content was measured according to Eq. (3), where $V_{1}(\mathrm{~mL})$ is the total volume of the supernatant, $V_{2}(\mathrm{~mL})$ is the volume of the measurement and DW (g) is the weight of the freeze-dried sample:

$\operatorname{MDA}(\mathrm{nmol} / \mathrm{g} \mathrm{DW})=\left[6.452 \times\left(\mathrm{OD}_{532}-\mathrm{OD}_{600}\right)-0.559 \times \mathrm{OD}_{450}\right] \times \mathrm{V}_{1} /\left(\mathrm{V}_{2} \times \mathrm{DW}\right)$.

Proline (Pro)

A 0.2-g sample was placed in a 10-ml test tube for Pro determination. (1) Added $5 \mathrm{~mL}$ of $3 \%$ aqueous sulfosalicylic acid solution and then transferred the sample to a boiling water bath for 20 min and obtained the Pro extraction after cooling. (2) A 2-mL extraction was moved to another test tube, $2 \mathrm{~mL}$ of glacial acetic acid and $2 \mathrm{~mL} 2.5 \%$ of acidic ninhydrin solution were added and the extraction was then transferred to a boiling water bath for $60 \mathrm{~min}$. (3) Added $4 \mathrm{~mL}$ of methylbenzene and the tube was shaken after cooling before being centrifuged at $5000 \mathrm{r} / \mathrm{min}$ for 13 according to the standard curve and Eq. (4), where $\mathrm{C}$ is the Pro content obtained from the 15 measurement and DW (g) is the weight of the freeze-dried sample: 
218 A 0.2-g sample was placed in a 50-mL test tube for determination of the soluble sugar. (1)

219 Added $20 \mathrm{~mL}$ deionized water and then transferred the tube to a boiling water bath for $20 \mathrm{~min}$. (2)

220 The tube was centrifuged at $3500 \mathrm{r} / \mathrm{min}$ for $10 \mathrm{~min}$ after cooling and the supernatant transferred

221 to a volumetric flask and diluted to $100 \mathrm{~mL}$ as an extraction solution (the residue was used later

222 to determine starch content). (3) Placed $1 \mathrm{~mL}$ of the extraction solution in another test tube and

223 added $4 \mathrm{~mL} 2 \%$ anthrone ethyl acetate, then placed the tube in a water bath at $90^{\circ} \mathrm{C}$ for $15 \mathrm{~min}$.

224 (4) After the tube had cooled and measured the absorbance of the extraction solution at $625 \mathrm{~nm}$.

225 The content of soluble sugar was calculated according to the standard curve and Eq. (5), where C

$226(\mu \mathrm{g})$ is the soluble sugar content according to the standard curve, $\mathrm{V}_{1}(\mathrm{~mL})$ is the total volume of

227 the extraction, $\mathrm{A}(\mathrm{mL})$ is the volume of the measurement and DW $(\mathrm{g})$ is the weight of the freeze-

228 dried sample:

229 Soluble sugar $(\%)=\left(\mathrm{C} \times \mathrm{V}_{1}\right) /\left(\mathrm{A} \times \mathrm{DW} \times 10^{6}\right) \times 100$.

230 Starch

231 The remaining residue was moved to a 20 -mL test tube for determination of the starch. (1)

232 Added $8 \mathrm{~mL}$ of hydrochloric acid and boiled the tube in a water bath for $45 \mathrm{~min}$, then transferred 233 the contents into a volumetric flask and added $8 \mathrm{~mL}$ sodium hydroxide and diluted it to $50 \mathrm{~mL}$.

234 (2) Placed $1 \mathrm{~mL}$ of the supernatant in a volumetric flask and diluted it to $25 \mathrm{~mL}$ as an extraction 235 solution. (3) Added $4 \mathrm{~mL}$ of anthrone to $1 \mathrm{~mL}$ extraction solution and placed the tube in a boiling 236 water bath for $5 \mathrm{~min}$. (4) After cooling, the absorbance was measured at $625 \mathrm{~nm}$. Starch content 237 was calculated according to the standard curve and Eq. (6), where $\mathrm{C}(\mu \mathrm{g})$ is the starch content 238 according to the standard curve, $\mathrm{V}(\mathrm{mL})$ is the total volume of the extraction solution, $\mathrm{A}(\mathrm{mL})$ is 239 the volume of the measurement and DW (g) is the weight of the freeze-dried sample:

240 Starch $(\%)=\mathrm{C} \times \mathrm{V} \times 0.9 /\left(\mathrm{A} \times \mathrm{DW} \times 10^{6}\right) \times 100$.

\section{Statistical Analyses}

242

243 Shapiro-Wilk test and Levene test showed that all data in this experiment obeyed a normal 244 distribution and satisfied the homogeneity of variance. Data in this study were subjected to a 245 two-way analysis of variance between treatments using SPSS 20.0 (SPSS Inc., Chicago, IL, 246 USA). Multiple range tests were performed using least significant differences, and differences 247 were considered significant at $p<0.05$ and $p<0.01$; ns was not significant. Principal component 248 analysis (PCA) was also conducted in this experiment.

\section{Results}

Biomass 
251

252

253

254

255

256

257

258

259

260

261

262

263

264

265

266

267

268

269

270

271

272

273

274

275

276

277

278

279

280

281

282

283

284

After 8 weeks, BGB and the ratio of BGB to AGB (R/S) growth differed significantly $(p<0.01)$ among SRE; nevertheless, there was no significance $(p>0.05)$ in AGB (Table 1). As rainfall intervals increased, BGB and R/S showed an increasing trend. $\mathrm{D}_{8}$ had the highest $\mathrm{BGB}$ and R/S (1.01 $\mathrm{g}$ and 0.68 , respectively) and these were significantly higher than those of $\mathrm{D}_{2}$. There was no major impact on $\mathrm{AGB}$ and $\mathrm{R} / \mathrm{S}(p>0.05)$ of the three $\mathrm{C}$ within the same water treatment (Table 1). The BGB of WL440 was $0.64 \mathrm{~g}$, which was significantly $(p<0.01)$ lower than that of WL168 and WL353. Further analysis showed significant interactions between SRE and C on R/S, and the former were found to have played a more important role (Table 2).

\section{Root Morphology}

SRE had a little effect $(p>0.05)$ on the primary root length (PRL) of alfalfa (Table 3$). \mathrm{D}_{2}$ had the longest lateral root length (LRL, $247 \mathrm{~cm}$ ) followed by $\mathrm{D}_{4}$ and $\mathrm{D}_{8}$. The crown diameters (CD) of $\mathrm{D}_{4}$ and $\mathrm{D}_{8}$ were 4.21 and $4.27 \mathrm{~mm}$, respectively, significantly $(p<0.05)$ wider than that of $\mathrm{D}_{2}$. RSA varied significantly $(p<0.01)$ among the three SRE; $\mathrm{D}_{8}$ had the minimum at $46.0 \mathrm{~cm}^{2} . \mathrm{D}_{4}$ and $\mathrm{D}_{8}$ had the same $\mathrm{RV}, 0.81 \mathrm{~cm}^{3}$, significantly $(p<0.01)$ larger than that of $\mathrm{D}_{2}$. Specific root length (SRL) was significantly $(p<0.01)$ inversely proportional to rainfall events. $\mathrm{D}_{2}$ had the greatest SRL, $452 \mathrm{~cm} / \mathrm{g}$, followed by $\mathrm{D}_{4}(335 \mathrm{~cm} / \mathrm{g})$ and $\mathrm{D}_{8}(221 \mathrm{~cm} / \mathrm{g})$. The three alfalfa $\mathrm{C}$ differed significantly $(p<0.01)$ in LRL, but not in PRL (Table 3). WL168 showed a significantly $(p<0.01)$ shorter LRL than WL440 and WL353. There was no evidence of a significant difference in CD and RSA between various C. The RV of WL168 and WL353 were both 0.80 $\mathrm{cm}^{3}$, a value significantly $(p<0.01)$ greater than that of WL440. The SRL of WL168 and WL353 were 277 and $278 \mathrm{~cm} / \mathrm{g}$, respectively, much lower than that of WL440. In every treatment combination $(\mathrm{SRE} \times \mathrm{C})$, the effect of rainfall events on root surface area and specific root length was greater than that of $\mathrm{C}$ (Table 2).

\section{Root System Architecture}

Basic information about the root system architecture in phase 1 is shown in Table 4. SRE had major effects $(p<0.01)$ on $\mathrm{RF}$, notably on $\mathrm{D}_{2}$ at 1572 . The ALL of $\mathrm{D}_{8}$ was $0.136 \mathrm{~cm}$, which was significantly longer than that of $\mathrm{D}_{2}$ and $\mathrm{D}_{4}$. Across the three SRE, the TI ranged from 0.600 to 0.634 and FD ranged from 1.390 to 1.469 . The TI and FD showed a reverse trend. A significant $(p<0.01)$ effect was detected for RF and ALL in various alfalfa $\mathrm{C}$, but there was no significant $(p>0.05)$ difference in TI and FD. WL353 had the maximum RF, 1390, which was significantly more than RF in WL168 and WL440. In contrast, the ALL of WL353 was $0.117 \mathrm{~cm}$, which was shorter than that of WL440. There were no major interactions between SRE and C in these four indicators (Table 4).

\section{Semi-lethal Temperature}


285

286

287

288

289

290

291

292

293

294

295

296

297

298

299

300

301

302

303

304

305

306

307

308

309

310

311

312

313

314

315

316

317

318

We observed that the cold resistance of alfalfa that had not undergone cold acclimation was relatively weak (Fig. 3). From phase 1 to phase 2 the $\mathrm{LT}_{50}$ of three SRE decreased by an average of $8.4^{\circ} \mathrm{C}$, and $\mathrm{D}_{2}$ had the largest decline at $6.1^{\circ} \mathrm{C}$. $\mathrm{D}_{8}$ had the lowest $\mathrm{LT}_{50}$ in both phases $(0.32$ and $-6.5^{\circ} \mathrm{C}$, respectively). Simultaneously, there were also significant $(p<0.01)$ differences in the $\mathrm{LT}_{50}$ in the two phases among the three alfalfa $\mathrm{C}$. The $\mathrm{LT}_{50}$ of WL168 decreased the most and reached $6.9^{\circ} \mathrm{C}$, followed by WL440 and WL353 $\left(5.9\right.$ and $5.8^{\circ} \mathrm{C}$, respectively). WL168 had the greatest cold resistance among the three $\mathrm{C}$ in phase 2 , and its $\mathrm{LT}_{50}$ was $-6.8^{\circ} \mathrm{C}$.

Principal component analysis (PCA, Kaiser-Meyer-Olkin (KMO) value was 0.728 and $p<0.01$ ) of 10 variables was used to identify the correlations between the variables and $\mathrm{LT}_{50}$, which were associated with the first two principal components (Fig. 4). Different colors denote different SRE and shapes refer to cultivars, and SREs play a more important role than cultivars in the difference of root traits. PCA axis 1 primarily reflected the morphological and spatial characteristics of root systems (LRL, RF and TI), which accounted for $37.56 \%$ of the overall variance in the standardized variables. Axis 2 mainly reflected the biomass of the alfalfa, explaining $16.82 \%$ of the standardized variance (Table 5). BGB, PRL and RSA were positively correlated with $\mathrm{CD}, \mathrm{RV}$ and FD, respectively. LRL was negatively correlated with BGB, CD and $\mathrm{RV}$; and TI was negatively correlated with RSA, RF and FD. $\mathrm{LT}_{50}$ was positively correlated with LRL, RSA, FD and RF, but inversely correlated with BGB, CD, RV and TI. Lateral root length, root forks and fractal dimension may have a greater contribution to the difference in $\mathrm{LT}_{50}$ between plants (Fig. 3).

\section{Physiological Indicators}

Compared with phase 1 , the MDA content showed an increasing trend in phase 2, and there were significant $(p<0.01)$ differences among various rainfall events (Fig. 5). The content of MDA of $D_{8}$ increased by $25 \%$ from phase 1 to phase 2 , which was less than that of $D_{4}(38 \%)$ and $D_{2}$ (59\%). There were no major changes in MDA content between the three $\mathrm{C}$ at $25^{\circ} \mathrm{C} / 20^{\circ} \mathrm{C}$ (day/night), but a significant difference appeared after the low-temperature experiment, and WL168 had a lower MDA content (100.9 $\left.\mathrm{nmol} \cdot \mathrm{g}^{-1} \mathrm{DW}\right)$.

The Pro content of the three rainfall events showed significant $(p<0.01)$ differences in the two phases (Fig. 6), but there was no significant difference among the three C. $\mathrm{D}_{8}$ had the highest Pro content at 2.61 and $3.26 \mathrm{mg} \cdot \mathrm{g}^{-1} \mathrm{DW}$ in phase 1 and phase 2 , respectively, followed by $\mathrm{D}_{4}(1.06$ and $\left.1.26 \mathrm{mg} \cdot \mathrm{g}^{-1} \mathrm{DW}\right)$ and $\mathrm{D}_{2}\left(0.31\right.$ and $\left.0.83 \mathrm{mg} \cdot \mathrm{g}^{-1} \mathrm{DW}\right)$.

The soluble sugar content of the three treatments increased after cold acclimation (Fig. 7). In the same phase, SRE had a significant $(p<0.01)$ impact on the soluble sugar content of alfalfa root, which was manifested as an increasing trend as the rainfall interval increased. There were major 
319 effects $(p<0.01)$ on the soluble sugar content of the two phases among the three alfalfa C.

320 WL440 had 118 and $127 \mathrm{mg} \cdot \mathrm{g}^{-1} \mathrm{DW}$ soluble sugar content in phase 1 and phase 2, respectively, 321 significantly higher than those of WL353 and WL168.

322 The starch content showed a downward trend at phase 2 for the three rainfall events in all three C 323 (Fig. 8). In the two within-phase comparisons, SRE had a significant $(p<0.01)$ impact on the 324 soluble sugar content of alfalfa roots, while the choice of $\mathrm{C}$ did not. The starch content of $\mathrm{D}_{8}$ was 32595.4 and $68.5 \mathrm{mg} \cdot \mathrm{g}^{-1} \mathrm{DW}$ in phase 1 and phase 2 , respectively, which was higher than in the 326 other two treatments.

327

\section{Discussion}

\section{Root Biomass}

330 Swemmer (2007) and Heisler-White (2008) demonstrated that rainfall interval and rainfall 331 amount are the key factors affecting the allocation of plant biomass. Rainfall events had no 332 significant effect on the AGB of alfalfa, while longer rainfall intervals increased BGB and R/S 333 (Table 1). This allometric growth relationship between root and shoot is an adaptive strategy by 334 plants to various soil water conditions (Padilla, 2009). Research has shown that longer rainfall 335 intervals can enhance the drought resistance of plants by promoting root growth and increasing 336 energy distribution to underground parts (Den Herder, 2010; Jangpromma, 2012; Padilla et al., 337 2009). There was little difference in AGB between the three $\mathrm{C}$, but the $\mathrm{C}$ with lower fall 338 dormancy level had higher BGB and R/S. Root biomass has been proven to be an indicator of 339 stress resistance (Bloor, 2018), and the $\mathrm{C}$ with a lower level of fall dormancy distributes more 340 energy to its roots. This also explains, to a certain extent, why alfalfa with a lower fall dormancy 341 score has better cold resistance (Oppelt, 2001; Xu et al., 2020b).

\section{Root Morphological Traits and Architecture}

343 Root plasticity determines the ability of plants to survive in the ever-changing soil

344 environment (Tian, 2014). The primary root mainly plays a role of fixing, storing and

345 transporting substances. It has a longer lifespan and slower metabolism, and there are no

346 significant differences in response to various rainfall events (Gruber, 2013). Lateral roots are the

347 main parts of the root system that absorb water and nutrient; they have a shorter lifespan,

348 stronger metabolism and lower resistance to abiotic stress, and are more sensitive to changing 349 environments (Li et al., 2020; Padilla et al., 2009; Withington, 2006). Through research on rice

350 (Oryza sativa L.) and arabidopsis (Arabidopsis thaliana L.), Pedersen (2021) found that a longer 351 rainfall event results in an overall altered root system that ranges from changes in root system 352 architecture, including fewer lateral roots and thicker primary root (Hodge, 2004; Schwab et al., 
353

354

355

356

357

358

359

360

361

362

363

364

365

366

367

368

369

370

371

372

373

374

375

376

377

378

379

380

381

382

383

384

385

386

387

388

1996). Larger root surface area and specific root length are beneficial to the root water absorption efficiency system (Hassouni, 2018), but attention should be given to the cost of water absorption under abiotic stress. Lateral roots are the most active part of the entire root system, and their faster turnover rate also increases the consumption of stored substances (Guo, 2004; Rewald, 2011; Withington et al., 2006). $\mathrm{D}_{8}$ has the shortest lateral root length (Table 3) and less consumption of stored substances, which can explain why alfalfa grown in intervals of longer rainfall showed better cold resistance in a subsequent low-temperature test (Fig. 2). Features such as a greater root volume and a small root surface area are evident after a longer rainfall interval, which enables plants to cope better with unpredictable soil conditions (Pedersen et al., 2021). Genotypes play an important role in the growth of plant roots under the same environment conditions and cultivation measures. Root systems of different cultivars respond differently to change in soil moisture (Tron et al., 2015). A field study was conducted to analyze the root system development ability of nine alfalfa cultivars; root biomass, primary root, lateral root, root surface area and root crown were significantly different among cultivars (Zhang et al., 2002). The three $\mathrm{C}$ presented various root trait responses to rainfall events: alfalfa with a low level of fall dormancy had shorter lateral roots and specific root length and a larger root volume, consistent with the results found by Filippo (2010). The spatial structure of a root system can further describe the distribution of roots in the soil. A study of the effects of rainfall on various species found that rainfall events have important effects on root system architecture, including in the roots of herbaceous plants (Kume, 2006). Root forks and average link length reflect the branching of plant roots. Root forks are related to water absorption efficiency (Bauhus, 2000) and average link length represents the space expansion ability of the root system (Walk, 2004). There is a negative correlation between root forks and average link length, and this depends on the soil conditions (Schenk \& Jackson, 2002a; 2002b). The results of rainfall events on alfalfa show that a root system under a longer rainfall interval has a longer average link length, while more root forks appear under shorter rainfall intervals (Kong, 2014). Root systems with a larger number of forks are more advantageous in resource-rich soil because they can quickly occupy the space available for rapid growth. Those with a longer average link length can improve competitiveness under water shortage because root overlap and unnecessary internal competition is reduced (Bauhus et al., 2000; Enquist \& Niklas, 2002; Guswa, 2010). We verified this tradeoff relationship between root forks and average link length in the three $\mathrm{C}$ (Table 4). Topological index and fractal dimensions are both parameters that describe the root system architecture. Lowfrequency heavy precipitation events are conducive to the development of herringbone branching in a root system (Table 4). Researcher has divided the branching patterns into dichotomous and herringbone according to the two extreme values of the TI, although the branching pattern of most plants falls between the two types (Fitter, 1986). A root system tends to dichotomous

Peer) reviewing PDF | (2021:03:59266:2:1:NEW 15 Jul 2021) 
389

390

391

392

393

394

395

396

397

398

399

400

401

402

403

404

405

406

407

408

409

410

411

412

413

414

415

416

417

418

419

420

421

422

423

branching when the plant is in high-nutrient soil and the TI is close to 0.5 ; the branching pattern tends to herringbone when resources are scarce and the TI is close to 1 (Fitter \& Stickland, 1992; Glimskär, 2000; Li et al., 2020; Lynch, 2019). Fractal dimensions are also important parameters in explaining the spatial structure of the root system. The change trend in fractal dimensions and root forks is consistent in describing the use of space by roots, and our results agreed with those of $\mathrm{Li}$ (2020) and Margitta (2005). Tron et al. (2015) modeled the transpiration of 48 root architecture types under 16 drought scenarios and different soil structures and textures; they reported that root architecture did not fully explain plant water use and suggested relating specific root architecture with genotype and other characteristics. Genotypes differ in their localization of root biomass at different depths under water stress condition; tolerant genotypes produce deeper and more vigorous roots in the search for water (Faroop et al., 2019). Manschadi et al. (2006) studied root architectural traits in the adaptation of wheat to water-limited conditions using a drought-tolerant and drought-susceptible genotype; the tolerant genotype developed a compact vertical root system allowing it to extract less water during early growth stages but more as the crop matured. WL168 has the smallest root forks and average link length, and this is consistent with the study of Faroop (2019).

\section{Semi-lethal Temperature and Root Traits}

Alfalfa has to undergo a low-temperature and short-photoperiod process to maximize its cold resistance (Theocharis et al., 2012), and this characteristic is shown in all three cultivars (Trischuk et al., 2014). Whether at normal temperature or undergoing low-temperature stress, the semi-lethal temperature of $\mathrm{D}_{8}$ was significantly lower than that of the other two (Fig. 2). Simultaneously, the cross acclimation of drought and low temperature has been confirmed in creeping bentgrass (Agrostis stolonifera L.) (Zhang et al., 2015) and alfalfa (Xu et al., 2020b), which provides theoretical support for improving cold resistance of alfalfa by water management. To further understand the relationship between water and cold resistance, we conducted a PCA analysis among root system traits and semi-lethal temperature (Fig. 4). The positive correlation factors that affect cold resistance of alfalfa mainly include below-ground biomass, crown diameter, root volume and topological index, while the increase in lateral root length, root surface area, root forks and fractal dimensions reduced the semi-lethal temperature. Some of our conclusions contradicted previous research (Johnson, 1996; Larson \& Smith, 1963; Liu et al., 2015; Smith, 1951), but these differences were mainly caused by environmental factors rather than by low-temperature stress. The root crown is the most sensitive part of the root system to temperature changes and is crucial to overwintering and regeneration (Bélanger, 2006; Janska et al., 2010). The plasticity of the root crown is an important strategy for alfalfa in its adaptation to the cold climate in northern regions. As the crown diameter increases, the cold resistance of 
424 alfalfa is gradually enhanced (Liu et al., 2015; Schwab et al., 1996). The root biomass is related 425 to the accumulation of organic matter and the herringbone branching is conducive to alfalfa's 426 absorption of deeper water in cold winter, which contribute to improving the plant's cold 427 resistance (Larson \& Smith, 1963; Viands, 1988). Longer lateral roots accelerate nutrient 428 consumption and are more susceptible to freezing under low-temperature stress (Schwab et al., 429 1996; Withington et al., 2006). Studies have confirmed that low-temperature stress inhibits plant 430 growth (Liu, 2019; Venzhik, 2011), but little is known about how these characteristics affect cold 431 resistance. The above analysis demonstrates the regulatory effect of rainfall events on root 432 system traits, and the next step is to manipulate these traits to enhance plant stress tolerance. It is 433 possible that gene editing technology may allow plant root traits to be changed and so permit better adaptation to low-temperature environments (Nakamichi, 2016).

\section{Root Physiological Indexes}

436 In winter, physiological regulation such as osmotic regulation, antioxidant regulation and induction of antifreeze gene expression is the most important way for plants to adapt to lowtemperature stress (Bertrand, 2017; Choudhury, 2017; Theocharis et al., 2012). Research has concluded that it is a significant correlation between cold resistance and the cell membrane, and plants with stronger cold resistance have a lower phase-transition temperature (Anower et al., 2016). MDA is the final product of cell membrane lipid redox, which can destroy the structure and function of proteins, nucleic acids and polysaccharides. Plants produce a larger amount of MDA under low-temperature stress, and its content has a significant negative correlation with the freezing tolerance of alfalfa (Choudhury et al., 2017; Xu et al., 2020a). In addition, excessive reactive oxygen species (ROS) can also affect cell activity. To reduce ROS damage, cells maintain their integrity through osmotic regulation (mostly of Pro, soluble sugar and starch) (Anower et al., 2016; Bertrand et al., 2017; Castonguay, 2011). Pro can act not only as an osmotic regulator or ROS scavenger, but also as a molecular chaperone to prevent cells from being damaged by low temperature (Castonguay et al., 2011; Kishor, 2005; Nakashima, 1998). Studies have proven that soluble sugar and starch are closely related to the freezing tolerance of alfalfa (Anower et al., 2016; Castonguay et al., 2006). Soluble sugar can improve the survival rate of alfalfa in winter in two ways: (1) it can act as an osmotic substance and cryoprotectant to lower the cell freezing point (Castonguay, 2013); and (2) it is a signal molecule that initiates a series of cold response mechanisms (Bertrand et al., 2017). Starch can be hydrolyzed into soluble sugar to improve the cold tolerance of alfalfa (Sengupta, 2015). In phase 2, the Pro and soluble sugar content of $\mathrm{D}_{8}$ was still higher than that of the other two cultivars, which indicated that cold acclimation would maximize the cold resistance of alfalfa, but also that a longer irrigation interval can accelerate this process (Xu et al., 2020a; Zhang et al., 2015). 
459

460 Conclusions

461 In our study, a low-frequency heavy precipitation significantly enhanced the cold resistance of 462 alfalfa compared with a high-frequency light precipitation. The increase in root biomass and 463 crown diameter, and the decrease of lateral root length and root surface area may have 464 contributed to the difference in $\mathrm{LT}_{50}$ among plants receiving the different treatments. A fewer 465 root forks and a bigger topological index may reduce the redundant consumption of the root 466 system, which is beneficial to improve the cold resistance of alfalfa in a low temperature 467 environment. Alfalfa with high fall dormancy grade has more below-ground biomass and less 468 lateral root, and these characteristics are conducive to rapid acquisition of cold resistance. 469 Simultaneously, a longer irrigation interval facilitated the accumulation of proline and soluble 470 sugar content. These conclusions provide support for winter water management of alfalfa and 471 selection of varieties in areas of high latitude.

472

473 Acknowledgements

474 Funding

475 This research was supported by the National Natural Science Foundation of China

476 (No.31772671). The funder had no role in study design, data collection and analysis, decision to 477 publish, or preparation of the manuscript.

478 Competing Interests

479 The authors declare there are no competing interests.

480 Author Contributions

481 Zhensong Li conceived and designed the experiments, performed the experiments, analyzed the

482 data, prepared figures and tables, authored or reviewed drafts of the paper, and approved the final 483 draft.

484 Liqiang Wan conceived and designed the experiments, reviewed drafts of the paper, and 485 approved the final draft.

486 Shuo Li performed the experiments, prepared figures and tables, and reviewed drafts of the paper.

487 Xianglin Li conceived and designed the experiments, and approved the final draft.

488 Feng He and Zongyong Tong designed the experiments, analyzed the data, and prepared figures 489 and tables.

490 We thank Professor Lihong Miao and Jing Cao for their advice and technical assistance in 491 conducting these studies.

492

493 
495

496

497

498

499

500

501

502

503

504

505

506

507

508

509

510

511

512

513

514

515

516

517

518

519

520

521

522

523

524

525

526

527

528

529

530

531

532

533

534

535

536

537

538

539

540

541

542

543

\section{References}

Anower MR, Fennell A, Boe A, Mott IW, Peel MD, Wu Y. 2016. Physiological and molecular characterisation of lucerne (Medicago sativa L.) germplasm with improved seedling freezing tolerance. Crop and Pasture Science 67:655-665 DOI 10.1071/CP15204.

Augspurger CK. 2009. Spring 2007 warmth and frost: phenology, damage and refoliation in a temperate deciduous forest. Functional Ecology 23:1031-1039 DOI 10.1111/j.1365-2435.2009.01587.x.

Bates LS. 1973. Rapid Determination of Free Proline for water-stress studies. Plant and Soil 39:205-207 DOI 10.1007/BF00018060.

Bauhus J, Khanna PK, Menden N. 2000. Aboveground and belowground interactions in mixed plantations of eucalyptus globulus and acacia mearnsii. Canadian Journal of Forest Research 30:1886-1894 DOI 10.1139/x00-141.

Be'langer G, Rochette P, Castonguay Y, Bootsma A, Mongrain D, Ryan DAJ. 2002. Climate change and winter survival of perennial forage crops in Eastern Canada. Agronomy Journal 94:11201130 DOI 10.2134/agronj2002.1120.

Bélanger G, Castonguay Y, Bertrand A, Dhont C, Rochette P, Couture L, Drapeau R, Mongrain D, Chalifour FP, Michaud R. 2006. Winter damage to perennial forage crops in eastern Canada: Causes, mitigation, and prediction. Canadian Journal of Plant Science 86:33-47 DOI 10.4141/p04-171.

Bertrand A, Bipfubusa M, Claessens A, Rocher S, Castonguay Y. 2017. Effect of photoperiod prior to cold acclimation on freezing tolerance and carbohydrate metabolism in alfalfa (Medicago sativa L.). Plant Science 264:122-128 DOI 10.1016/j.plantsci.2017.09.003.

Bloor JMG, Zwicke M, Picon-Cochard C. 2018. Drought responses of root biomass provide an indicator of soil microbial drought resistance in grass monocultures. Applied Soil Ecology 126:160-164 DOI 10.1016/j.apsoil.2018.02.014.

Bouma TJ, Nielsen KL, Hal JV, Koutstaal B. 2001. Root system topology and diameter distribution of species from habitats differing in inundation frequency. Functional Ecology 15:360-369 DOI 10.1046/j.1365-2435.2001.00523.x.

Buysse J, Merckx R. 1993. An improved colorimetric method to quantify sugar content of plant tissue. Journal of Experimental Botany 44:1627-1629 DOI 10.1093/jxb/44.10.1627.

Carol KA. 2013. Reconstructing patterns of temperature, phenology, and frost damage over 124 years. Ecology 94:41-50 DOI 10.1890/12-0200.1.

Castonguay Y, Bertrand A, Michaud R, Laberge S. 2011. Cold-induced biochemical and molecular changes in alfalfa populations selectively improved for freezing tolerance. Crop Science 51:21322144 DOI 10.2135/cropsci2011.02.0060.

Castonguay Y, Dube MP, Cloutier J, Bertrand A, Michaud R, Laberge S. 2013. Molecular physiology and breeding at the crossroads of cold hardiness improvement. Physiologia Plantarum 147:64-74 DOI 10.1111/j.1399-3054.2012.01624.x.

Castonguay Y, Laberge S, Brummer EC, Volenec JJ. 2006. Alfalfa winter hardiness: A research retrospective and integrated perspective. Advances in Agronomy 90:203-265 DOI 10.1016/S0065-2113(06)90006-6.

CCAF. 2001. Impact of climate change on risk of winter damage to agricultural perennial plants.

Choudhury FK, Rivero RM, Blumwald E, Mittler R. 2017. Reactive oxygen species, abiotic stress and stress combination. The Plant Journal 90:856-867 DOI 10.1111/tpj.13299.

Comas LH, Becker SR, Cruz VM, Byrne PF, Dierig DA. 2013. Root traits contributing to plant productivity under drought. Frontiers in Plant Science 4:442 DOI 10.3389/fpls.2013.00442.

Crews TE, Peoples MB. 2004. Legume versus fertilizer sources of nitrogen: ecological tradeoffs and human needs. Agriculture, Ecosystems \& Environment 102:279-297 DOI 10.1016/j.agee.2003.09.018.

Dannowski M, Block A. 2005. Fractal geometry and root system structures of heterogeneous plant

Peer] reviewing PDF | (2021:03:59266:2:1:NEW 15 Jul 2021) 
544

545

546

547

548

549

550

551

552

553

554

555

556

557

558

559

560

561

562

563

564

565

566

567

568

569

570

571

572

573

574

575

576

577

578

579

580

581

582

583

584

585

586

587

588

589

590

591

592

593

594

communities. Plant and Soil 272:61-76 DOI 10.1007/s11104-004-3981-2.

Den Herder G, Van Isterdael G, Beeckman T, De Smet I. 2010. The roots of a new green revolution. Trends in Plant Science 15:600-607 DOI 10.1016/j.tplants.2010.08.009.

Dhindsa RS, Plumb-Dhindsa P, Thorpe TA. 1981. Leaf senescence: Correlated with increased levels of membrane permeability and lipid peroxidation, and decreased levels of superoxide dismutase and catalase. Journal of Experimental Botany 32:93-101 DOI 10.1093/jxb/32.1.93.

Enquist BJ, Niklas KJ. 2002. Global allocation rules for patterns of biomass partitioning in seed plants. Science 295:1517-1520 DOI 10.1126/science.1066360.

Fang JY, Yu GR, Liu LL, Hu SJ, Chapin FS, 3rd. 2018. Climate change, human impacts, and carbon sequestration in China. Proceding of the National Academy of Science of the Untied States of America 115:4015-4020 DOI 10.1073/pnas.1700304115.

Farooq M, Hussain M, Ul-Allah S, Siddique Kadambot HM. 2019. Physiological and agronomic approaches for improving water-use efficiency in crop plants. Agricultural Water Management 219: 95-108 DOI 10.1016/j.agwat.2019.04.010

Fitter AH. 1986. The topology and geometry of plant root systems influence of watering rate on root system topology in Trifolium pratense. Annals of Botany 58:91-101 DOI 10.1093/oxfordjournals.aob.a087191.

Fitter AH, Stickland TR. 1992. Fractal characterization of root system architecture. Functional Ecology 6:632-635 DOI 10.2307/2389956.

Fitter AH, Stickland TR, Harvey ML, Wilson GW. 1991. Architectural analysis of plant root systems 1. Architectural correlates of exploitation efficiency. New Phytologist 118:375-382 DOI 10.1111/j.1469-8137.1991.tb00018.x

Glimskär A. 2000. Estimates of root system topology of five plant species grown at steady-state nutrition. Plant and Soil 227:249-256 https://doi.org/10.1023/A:1026531200864.

Gruber BD, Giehl RF, Friedel S, von Wiren N. 2013. Plasticity of the Arabidopsis root system under nutrient deficiencies. Plant Physiology 163:161-179 DOI 10.1104/pp.113.218453.

Guo DL, Mitchell RJ, Hendricks JJ. 2004. Fine root branch orders respond differentially to carbon source-sink manipulations in a longleaf pine forest. Oecologia 140:450-457 DOI 10.1007/s00442-004-1596-1.

Guswa AJ. 2010. Effect of plant uptake strategy on the water-optimal root depth. Water Resources Research 46:1-5 DOI 10.1029/2010wr009122.

Harrar K, Hamami L. 2007. The box counting method for evaluate the fractal dimension in radiographic images. 6th International Conference on Circuits, Systems, Electronics, Control and Signal Processing (CSECS'07), Cairo, Egypt 385-389 DOI 10.1.1.499.1495.

Hassouni K, Alahmad S, Belkadi B, Filali-Maltouf A, Hickey LT, Bassi FM. 2018. Root system architecture and its association with yield under different water regimes in durum wheat. Crop Science 58:2331-2346 DOI 10.2135/cropsci2018.01.0076.

He XT. 2011. China grass industry statistics. Beijing:National Animal Husbandry Terminus. [in Chinese]

Heisler-White JL, Knapp AK, Kelly EF. 2008. Increasing precipitation event size increases aboveground net primary productivity in a semi-arid grassland. Oecologia 158:129-140 DOI 10.1007/s00442-008-1116-9.

Hodge A. 2004. The plastic plant: root responses to heterogeneous supplies of nutrients. New Phytologist 162:9-24 DOI 10.1111/j.1469-8137.2004.01015.x.

Jangpromma N, Thammasirirak S, Jaisil P, Songsri P. 2012. Effects of drought and recovery from drought stress on above ground and root growth, and water use efficiency in sugarcane (Saccharum officinarum L.). Australian Journal of Crop Science 6:1298-1304 DOI cabdirect/abstract/20123284689.

Janska A, Marsik P, Zelenkova S, Ovesna J. 2010. Cold stress and acclimation - what is important for metabolic adjustment? Plant Biology 12:395-405 DOI 10.1111/j.1438-8677.2009.00299.x.

Ji HT, Xiao LJ, Xia YM, Song H, Liu B, Tang L, Cao WX, Zhu Y, Liu LL. 2017. Effects of jointing and booting low temperature stresses on grain yield and yield components in wheat. Agricultural

Peer] reviewing PDF | (2021:03:59266:2:1:NEW 15 Jul 2021) 
595

596

597

598

599

600

601

602

603

604

605

606

607

608

609

610

611

612

613

614

615

616

617

618

619

620

621

622

623

624

625

626

627

628

629

630

631

632

633

634

635

636

637

638

639

640

641

642

643

644

645

and Forest Meteorology 243:33-42 DOI 10.1016/j.agrformet.2017.04.016.

Johnson D, Marquez-Ortiz JJ, Barnes DK, Lamb JFS. 1996. Inheritance of root traits in alfalfa. Crop Science 36:1482-1487 DOI 10.2135/cropsci1996.0011183X003600060011x.

Kishor PBK, Sangam S, Amrutha RN, Laxmi PS, Naidu KR, Rao KRSS, Rao S, Reddy KJ, Theriappan P, Sreenivasulu N. 2005. Regulation of proline biosynthesis degradation uptake and transport in higher plants its implications in plant growth and abiotic stress tolerance. Current Science 88:424-438 DOI stable/24110209.

Kong R, Henry H. 2019a. Cross acclimation effects of spring freezing and summer drought on plant functional groups and ecosystem properties. Environmental and Experimental Botany 164:52-57 DOI 10.1016/j.envexpbot.2019.05.001.

Kong R, Henry H. 2019b. Interactions of plant growth responses to spring freezing and summer drought: a multispecies comparison. American Journal of Botany 106:531-539 DOI 10.1002/ajb2.1264.

Kong XP, Zhang ML, De Smet I, Ding ZJ. 2014. Designer crops: optimal root system architecture for nutrient acquisition. Trends in Biotechnol 32:597-598 DOI 10.1016/j.tibtech.2014.09.008.

Kume T, Sekiya N, Yano K. 2006. Heterogeneity in spatial P-distribution and foraging capability by Zea mays: effects of patch size and barriers to restrict root proliferation within a patch. Annals of Botany 98:1271-1277 DOI 10.1093/aob/mcl216.

Larson KL, Smith D. 1963. Association of various morphological character and seed germination with the winter hardiness of alfalfa. Crop Science 3:234-237 DOI 10.2135/cropsci1963.0011183X000300030018x.

Li S, Wan LQ, Nie ZN, Li XL. 2020. Fractal and topological analyses and antioxidant defense systems of alfalfa (Medicago sativa L.) root system under drought and rehydration regimes. Agronomy 10:805-826 DOI 10.3390/agronomy10060805.

Liu LL, Ji HT, An JP, Shi KJ, Ma JF, Liu B, Tang L, Cao WX, Zhu Y. 2019. Response of biomass accumulation in wheat to low-temperature stress at jointing and booting stages. Environmental and Experimental Botany 157:46-57 DOI 10.1016/j.envexpbot.2018.09.026.

Liu ZY, Li XL, Li F, Tao Y, Liu L, Wang ZL, Sun QZ. 2015. Response of alfalfa root traits to fall dormancy and its effect on winter hardiness. Scientia Agricultura Sinica 48:1689-1701 DOI 10.3864/j.issn.0578-1752.2015.09.03. [In Chinese]

Lynch JP. 2019. Root phenotypes for improved nutrient capture: an underexploited opportunity for global agriculture. New Phytologist 223:548-564 DOI 10.1111/nph.15738.

Manschadi AM, Christopher J, deVoil P, Hammer GL. 2006. The role of root architectural traits in adaptation of wheat to water-limited environments. Functional Plant Biology 33:823-837 DOI 10.1071/fp06055.

Nakamichi N, Takao S, Kudo T, Kiba T, Wang Y, Kinoshita T, Sakakibara H. 2016. Improvement of arabidopsis biomass and cold, drought and salinity stress tolerance by modified circadian clock-associated PSEUDO-RESPONSE REGULATORs. Plant and Cell Physiology 57:10851097 DOI 10.1093/pcp/pcw057.

Nakashima K, Satoh R, Kiyosue T, Yamaguchi-Shinozaki K, Shinozaki K. 1998. A gene encoding proline dehydrogenase is not only induced by proline and hypoosmolarity, but is also developmentally regulated in the reproductive organs of arabidopsis. Plant Physiology 118:12331241 DOI: https://doi.org/10.1104/pp.118.4.1233

Oppelt AL, Kurth W, Godbold DL. 2001. Topology, scaling relations and Leonardo's rule in root systems from African tree species. Tree Physiology 21:117-128 DOI 10.1093/treephys/21.23.117.

Padilla FM, Miranda JD, Jorquera MJ, Pugnaire FI. 2009. Variability in amount and frequency of water supply affects roots but not growth of arid shrubs. Plant Ecology 204:261-270 DOI 10.1007/s11258-009-9589-0.

Pedersen O, Sauter M, Colmer TD, Nakazono M. 2021. Regulation of root adaptive anatomical and morphological traits during low soil oxygen. New Phytologist 229:42-49 DOI 10.1111/nph.16375.

Rewald B, Ephrath JE, Rachmilevitch S. 2011. A root is a root is a root? Water uptake rates of Citrus

Peer] reviewing PDF | (2021:03:59266:2:1:NEW 15 Jul 2021) 
646

647

648

649

650

651

652

653

654

655

656

657

658

659

660

661

662

663

664

665

666

667

668

669

670

671

672

673

674

675

676

677

678

679

680

681

682

683

684

685

686

687

688

689

690

691

692

693

694

695

696

root orders. Plant Cell and Environment 34:33-42 DOI 10.1111/j.1365-3040.2010.02223.x.

Rimi F, Macolino S, Leinauer B, Lauriault LM, Ziliotto U. 2010. Alfalfa yield and morphology of three fall-dormancy categories farvested at two phenological stages in a subtropical climate. Agronomy Journal 102:1578-1585 DOI 10.2134/agronj2010.0193.

Robertson GP, Paul EA, Harwood RR. 2000. Greenhouse gases in intensive agriculture: Contributions of individual gases to the radiative forcing of the atmosphere. Science 289:1922-1925 DOI 10.1126/science.289.5486.1922.

Russelle MP. 2001. Alfalfa. American Scientist 89:252-261 DOI stable/27857472.

Schenk HJ, Jackson RB. 2002a. The global biogeography of roots. Ecological Monographs 72:311-328 http://dx.doi.org/10.1890/0012-9615(2002)072[0311:TGBOR]2.0.CO;2

Schenk HJ, Jackson RB. 2002b. Rooting depths, lateral root spreads and below-ground/ above-ground allometries of plants in water-limited ecosystems. Journal of Ecology 90:480-494 DOI 10.1046/j.1365-2745.2002.00682.x.

Schwab PM, Barnes DK, Sheaffer CC, Li PH. 1996. Factors affecting a laboratory evaluation of alfalfa cold tolerance. Crop Science 36:318-324 DOI 10.2135/cropsci1996.0011183X003600020018x.

Schwinning S, Sala OE. 2004. Hierarchy of responses to resource pulses in arid and semi-arid ecosystems. Oecologia 141:211-220 DOI 10.1007/s00442-004-1520-8.

Schwinning S, Starr BI, Ehleringer JR. 2003. Dominant cold desert plants do not partition warm season precipitation by event size. Oecologia 136:252-260 DOI 10.1007/s00442-003-1255-y.

Sengupta S, Mukherjee S, Basak P, Majumder AL. 2015. Significance of galactinol and raffinose family oligosaccharide synthesis in plants. Frontiers in Plant Science 6:656 DOI 10.3389 /fpls.2015.00656

Smith D. 1951. Root branching of alfalfa varieties and strains. Agronomy Journal 43:573-575.

Swemmer AM, Knapp AK, Snyman HA. 2007. Intra-seasonal precipitation patterns and above-ground productivity in three perennial grasslands. Journal of Ecology 95:780-788 DOI 10.1111/j.13652745.2007.01237.x.

Theocharis A, Clement C, Barka EA. 2012. Physiological and molecular changes in plants grown at low temperatures. Planta 235:1091-1105 DOI 10.1007/s00425-012-1641-y.

Tian HY, De Smet I, Ding ZJ. 2014. Shaping a root system: regulating lateral versus primary root growth. Trends in Plant Science 19:426-431 DOI 10.1016/j.tplants.2014.01.007.

Trischuk RG, Schilling BS, Low NH, Gray GR, Gusta LV. 2014. Cold acclimation, de-acclimation and re-acclimation of spring canola, winter canola and winter wheat: The role of carbohydrates, cold-induced stress proteins and vernalization. Environmental and Experimental Botany 106:156163 DOI 10.1016/j.envexpbot.2014.02.013.

Tron S, Bodner G, Laio F, Ridolfi D. 2015. Can diversity in root architecture explain plant water use efficiency? A modeling study. Ecological Modelling 312:200-210 DOI 10.1016/j.ecolmodel.2015.05.028.

Venzhik YV, Titov AF, Talanova VV, Frolova SA, Talanov AV, Nazarkina YA. 2011. Influence of lowered temperature on the resistance and functional activity of the photosynthetic apparatus of wheat plants. Biology Bulletin 38:132-137 DOI 10.1134/s1062359011020142.

Viands DR. 1988. Variability and selection for characters associated with root regeneration capability in alfalfa. Crop Science 28:232-236 DOI 10.2135/cropsci1988.0011183X002800020009x.

Walk TC, Van Erp E, Lynch JP. 2004. Modelling applicability of fractal analysis to efficiency of soil exploration by roots. Annals of Botany 94:119-128 DOI 10.1093/aob/mch116.

Withington JM, Reich PB, Oleksyn J, Eissenstat DM. 2006. Comparisons of structure and life span in roots and leaves among temperate trees. Ecological Monographs 76:381-397 DOI 10.1890/00129615(2006)076[0381:COSALS]2.0.CO;2.

Xu HY, Li ZY, Tong ZY, He F, Li XL. 2020a. Metabolomic analyses reveal substances that contribute to the increased freezing tolerance of alfalfa (Medicago sativa L.) after continuous water deficit. BMC Plant Biology 20:1-15 DOI 10.1186/s12870-019-2233-9.

Xu HY, Tong ZY, He F, Li XL. 2020b. Response of alfalfa (Medicago sativa L.) to abrupt chilling as

Peer] reviewing PDF | (2021:03:59266:2:1:NEW 15 Jul 2021) 
697

698

699

700

701

702

703

704

705

706

707

708

709 reflected by changes in freezing tolerance and soluble sugars. Agronomy 10:255-270 DOI 10.3390/agronomy 10020255 .

Yang XF, Liang QW, Na RS, Zhang QQ, Pan XL. 2019. Technical regulations for overwintering management of water-saving irrigation of alfalfa on sandy land in Central and Eastern Inner Mongolia. Modern Animal Husbandry 10:37-38 DOI 10.14070/j.cnki.15-1150.2019.10.015. [In Chinese]

Zhang LJ, Zhong TX, Xu LX, Han LB, Zhang XZ. 2015. Water deficit irrigation impacts on antioxidant metabolism associated with freezing tolerance in creeping bentgrass. Journal of the American Society for Horticultural Science 140:323-332 DOI: 10.21273/JASHS.140.4.323.

Zhang ZH, Xiao JY, Hou FJ, Lu N. 2002. Root system development ability of several alfalfa cultivars in the hilly and valley regions of Loess Plateau. Chinese Journal of Applied Ecology 8:1007-1012 DOI http://61.133.213.143/uploadfile/pdf/2010-7/201072992813352.pdf . 


\section{Table $\mathbf{1}$ (on next page)}

Above-ground biomass, below-ground biomass and the ratio of below-ground biomass to above-ground biomass among simulated rainfall events or cultivars in phase 1.

Note: Mean values $(n=18) \pm$ standard errors of the mean are shown. Different letters represent a significant difference under various SRE and C; ns indicates the difference is not significant; and $p<0.05$ and $p<0.01$ indicate significant difference at 0.05 and 0.01 levels, respectively. $A G B$, above-ground biomass; $B G B$, below-ground biomass; $R / S$, the ratio of $B G B$ to AGB; SRE, simulated rainfall events; C, cultivars. 
1 Table 1 Above-ground biomass, below-ground biomass and the ratio of below-ground 2 biomass to above-ground biomass among simulated rainfall events or cultivars in phase 1.

\begin{tabular}{ccccc}
\hline \multicolumn{2}{c}{ Treatments } & AGB $(\mathrm{g})$ & BGB $(\mathrm{g})$ & $\mathrm{R} / \mathrm{S}$ \\
\hline \multirow{2}{*}{ SRE } & $\mathrm{D}_{2}$ & $1.60 \pm 0.26$ & $0.64 \pm 0.25^{\mathrm{b}}$ & $0.45 \pm 0.14^{\mathrm{b}}$ \\
& $\mathrm{D}_{4}$ & $1.74 \pm 0.34$ & $0.87 \pm 0.30^{\mathrm{a}}$ & $0.51 \pm 0.14^{\mathrm{b}}$ \\
& $\mathrm{D}_{8}$ & $1.58 \pm 0.23$ & $1.01 \pm 0.27^{\mathrm{a}}$ & $0.68 \pm 0.17^{\mathrm{a}}$ \\
& $p$ value & $\mathrm{ns}$ & $<0.01$ & $<0.01$ \\
$\mathrm{C}$ & WL168 & $1.68 \pm 0.19$ & $0.95 \pm 0.32^{\mathrm{a}}$ & $0.57 \pm 0.21$ \\
& WL353 & $1.76 \pm 0.24$ & $0.93 \pm 0.23^{\mathrm{a}}$ & $0.56 \pm 0.12$ \\
& WL440 & $1.47 \pm 0.35$ & $0.64 \pm 0.20^{\mathrm{b}}$ & $0.48 \pm 0.16$ \\
& $p$ value & $\mathrm{ns}$ & $<0.01$ & $\mathrm{~ns}$ \\
\hline
\end{tabular}

3 Note: Mean values $(\mathrm{n}=18) \pm$ standard errors of the mean are shown. Different letters represent a 4 significant difference under various SRE and C; ns indicates the difference is not significant; and $5 p<0.05$ and $p<0.01$ indicate significant difference at 0.05 and 0.01 levels, respectively. AGB, 6 above-ground biomass; BGB, below-ground biomass; R/S, the ratio of BGB to AGB; SRE, 7 simulated rainfall events; $C$, cultivars. 


\section{Table 2 (on next page)}

Interaction and simple effect analysis of simulated rainfall events and cultivars on biomass, root traits and $\mathrm{LT}_{50}$ among in phase 1 .

Note: Significance (Sig.) and partial eta squared (PES) are shown, and ns indicates the difference is not significant. - indicates there was no significant interaction between simulated rainfall events and cultivars. PRL, primary root length; $L R L$, lateral root length; $C D$, crown diameter; RSA, root surface area; RV, root volume; SRL, specific root length; RF, root forks; ALL, average link length; TI, topological index; FD, fractal dimensions. 
1 Table 2 Interaction and simple effect analysis of simulated rainfall events and cultivars on

2 biomass, root traits and $\mathrm{LT}_{\mathbf{5 0}}$ among in phase 1.

\begin{tabular}{cccccc}
\hline & \multicolumn{2}{l}{ SRE $\times$ C } & \multicolumn{2}{c}{ SRE } & \multicolumn{2}{c}{ Cig. } & PES \\
\cline { 2 - 6 } & Sig. & Sig. & PES & - & - \\
ABG & $\mathrm{ns}$ & - & - & - & - \\
BGB & $\mathrm{ns}$ & - & - & 0.113 & 0.085 \\
R/S & $<0.05$ & $<0.01$ & 0.250 & - & - \\
PRL & $\mathrm{ns}$ & - & - & - & - \\
LRL & $\mathrm{ns}$ & - & - & - & - \\
CD & $\mathrm{ns}$ & & - & 0.074 & 0.101 \\
RSA & $<0.05$ & $<0.01$ & 0.452 & - & - \\
RV & $\mathrm{ns}$ & - & - & -0.01 & 0.349 \\
SRL & $<0.01$ & $<0.01$ & 0.414 & - & - \\
RF & $\mathrm{ns}$ & - & - & - & - \\
ALL & $\mathrm{ns}$ & - & - & - & - \\
TI & $\mathrm{ns}$ & - & - & - & - \\
FD & $\mathrm{ns}$ & - & - & - & - \\
LT50-phase1 & $\mathrm{ns}$ & - & - & - & - \\
LT50-phase2 & $\mathrm{ns}$ & - & - & & -
\end{tabular}

3 Note: Significance (Sig.) and partial eta squared (PES) are shown, and ns indicates the difference

4 is not significant. - indicates there was no significant interaction between simulated rainfall

5 events and cultivars. PRL, primary root length; LRL, lateral root length; CD, crown diameter;

6 RSA, root surface area; RV, root volume; SRL, specific root length; RF, root forks; ALL,

7 average link length; TI, topological index; FD, fractal dimensions. 


\section{Table 3(on next page)}

Root morphological traits among simulated rainfall events or cultivars in phase 1.

Note: Mean values $(n=18) \pm$ standard errors of the mean are shown. Different letters represent a significant difference under various SRE and C; ns indicates the difference is not significant; and $p<0.05$ and $p<0.01$ indicate significant differences at 0.05 and 0.01 levels, respectively. 
1 Table 3 Root morphological traits among simulated rainfall events or cultivars in phase 1.

\begin{tabular}{cccccccc}
\hline \multicolumn{2}{c}{ Treatments } & PRL $(\mathrm{cm})$ & LRL $(\mathrm{cm})$ & CD $(\mathrm{mm})$ & RSA $\left(\mathrm{cm}^{2}\right)$ & $\mathrm{RV}\left(\mathrm{cm}^{3}\right)$ & SRL $(\mathrm{cm} / \mathrm{g})$ \\
\hline \multirow{2}{*}{$\mathrm{SRE}$} & $\mathrm{D}_{2}$ & $42.40 \pm 2.5$ & $247 \pm 15^{\mathrm{a}}$ & $3.76 \pm 0.75^{\mathrm{b}}$ & $66.3 \pm 9.9^{\mathrm{a}}$ & $0.74 \pm 0.06^{\mathrm{b}}$ & $452 \pm 109^{\mathrm{a}}$ \\
& $\mathrm{D}_{4}$ & $43.46 \pm 2.9$ & $214 \pm 11^{\mathrm{b}}$ & $4.21 \pm 0.59^{\mathrm{a}}$ & $57.3 \pm 9.5^{\mathrm{b}}$ & $0.81 \pm 0.07^{\mathrm{a}}$ & $335 \pm 67^{\mathrm{b}}$ \\
& $\mathrm{D}_{8}$ & $43.28 \pm 3.6$ & $162 \pm 11^{\mathrm{c}}$ & $4.27 \pm 0.56^{\mathrm{a}}$ & $46.0 \pm 9.5^{\mathrm{c}}$ & $0.81 \pm 0.04^{\mathrm{a}}$ & $221 \pm 48^{\mathrm{c}}$ \\
& $p$ value & $\mathrm{ns}$ & $<0.01$ & $<0.05$ & $<0.01$ & $<0.01$ & $<0.01$ \\
$\mathrm{C}$ & WL168 & $42.49 \pm 2.6$ & $185 \pm 17^{\mathrm{b}}$ & $3.88 \pm 0.76$ & $57.8 \pm 3.6$ & $0.80 \pm 0.07^{\mathrm{a}}$ & $277 \pm 69^{\mathrm{b}}$ \\
& WL353 & $42.98 \pm 2.9$ & $214 \pm 18^{\mathrm{a}}$ & $4.24 \pm 0.69$ & $59.5 \pm 5.0$ & $0.80 \pm 0.05^{\mathrm{a}}$ & $278 \pm 49^{\mathrm{b}}$ \\
& WL440 & $43.68 \pm 3.4$ & $225 \pm 24^{\mathrm{a}}$ & $4.12 \pm 0.51$ & $52.3 \pm 5.9$ & $0.75 \pm 0.08^{\mathrm{b}}$ & $453 \pm 114^{\mathrm{a}}$ \\
& & $\mathrm{ns}$ & $<0.01$ & $\mathrm{~ns}$ & $\mathrm{~ns}$ & $<0.01$ & $<0.01$ \\
\hline
\end{tabular}

2 Note: Mean values $(\mathrm{n}=18) \pm$ standard errors of the mean are shown. Different letters represent a

3 significant difference under various SRE and C; ns indicates the difference is not significant; and

$4 p<0.05$ and $p<0.01$ indicate significant differences at 0.05 and 0.01 levels, respectively. 


\section{Table 4 (on next page)}

Root spatial traits between simulated rainfall events or cultivars in phase 1 .

Note: Mean values $(n=18) \pm$ standard errors of the mean are shown. Different letters represent a significant difference under various SRE and C; ns indicates the difference is not significant; and $p<0.05$ and $p<0.01$ indicate significant difference at the level of 0.05 and 0.01 , respectively. 
1 Table 4 Root spatial traits between simulated rainfall events or cultivars in phase 1.

\begin{tabular}{cccccc}
\hline \multicolumn{2}{c}{ Treatments } & RF & ALL $(\mathrm{cm})$ & TI & FD \\
\hline SRE & $\mathrm{D}_{2}$ & $1572 \pm 242^{\mathrm{a}}$ & $0.119 \pm 0.015^{\mathrm{b}}$ & $0.600 \pm 0.020^{\mathrm{b}}$ & $1.469 \pm 0.043^{\mathrm{a}}$ \\
& $\mathrm{D}_{4}$ & $1325 \pm 275^{\mathrm{b}}$ & $0.117 \pm 0.020^{\mathrm{b}}$ & $0.621 \pm 0.016^{\mathrm{a}}$ & $1.444 \pm 0.034^{\mathrm{a}}$ \\
& $\mathrm{D}_{8}$ & $854 \pm 118^{\mathrm{c}}$ & $0.136 \pm 0.018^{\mathrm{a}}$ & $0.634 \pm 0.022^{\mathrm{a}}$ & $1.390 \pm 0.042^{\mathrm{b}}$ \\
& $p$ value & $<0.01$ & $<0.05$ & $<0.01$ & $<0.01$ \\
$\mathrm{C}$ & WL168 & $1171 \pm 273^{\mathrm{b}}$ & $0.107 \pm 0.021^{\mathrm{b}}$ & $0.622 \pm 0.023$ & $1.437 \pm 0.050$ \\
& WL353 & $1390 \pm 468^{\mathrm{a}}$ & $0.117 \pm 0.028^{\mathrm{b}}$ & $0.610 \pm 0.023$ & $1.447 \pm 0.045$ \\
& WL440 & $1191 \pm 303^{\mathrm{b}}$ & $0.147 \pm 0.020^{\mathrm{a}}$ & $0.623 \pm 0.023$ & $1.419 \pm 0.044$ \\
& $p$ value & $<0.01$ & $<0.01$ & $\mathrm{~ns}$ & $\mathrm{~ns}$ \\
\hline
\end{tabular}

2 Note: Mean values $(\mathrm{n}=18) \pm$ standard errors of the mean are shown. Different letters represent a

3 significant difference under various SRE and C; ns indicates the difference is not significant; and $4 p<0.05$ and $p<0.01$ indicate significant difference at the level of 0.05 and 0.01 , respectively. 
Table 5 (on next page)

Component Matrix of the first two principal components. 
Table 5 Component Matrix of the first two principal components.

\begin{tabular}{ccc}
\hline & \multicolumn{2}{c}{ Component } \\
\cline { 2 - 3 } & 1 & 2 \\
\hline AB & 0.057 & 0.818 \\
BB & -0.403 & 0.537 \\
PRL & -0.121 & 0.195 \\
LRL & 0.826 & -0.288 \\
CD & -0.199 & 0.348 \\
RSA & 0.779 & 0.375 \\
RV & -0.420 & 0.544 \\
RF & 0.910 & 0.095 \\
TI & -0.624 & -0.099 \\
FD & 0.746 & 0.387 \\
\hline
\end{tabular}

2 
Figure 1

Schematic diagram of experiment processing and sampling.

$25 / 20^{\circ} \mathrm{C}$ and $5 / 0^{\circ} \mathrm{C}$ represent the temperature of alfalfa during normal growth and cold acclimation, respectivel.

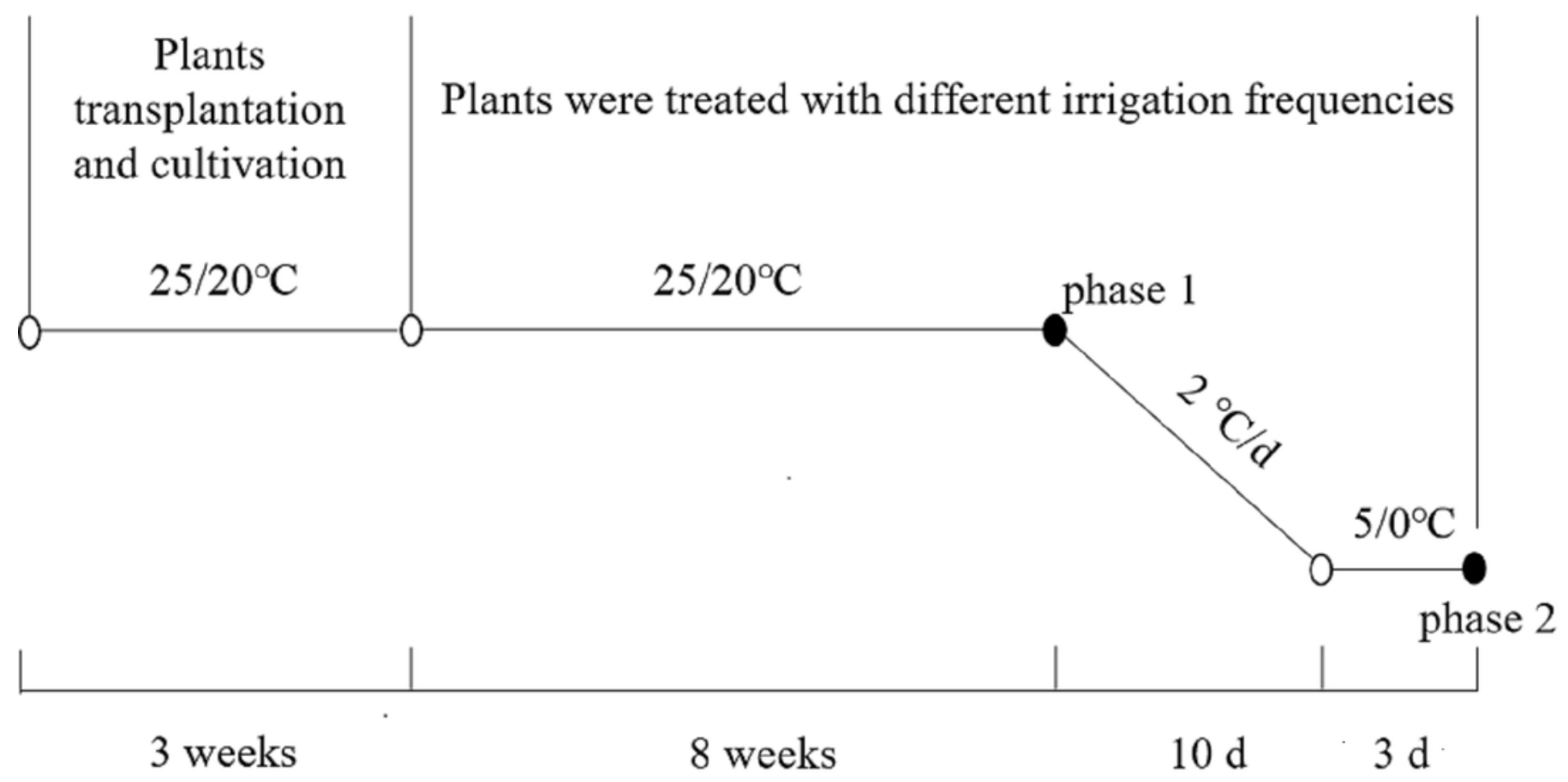




\section{Figure 2}

Scanning image of root system under three simulated rainfall events.

$D_{2}, D_{4}$ and $D_{8}$ represent irrigation once every second day, every four days and every eight days respectively .

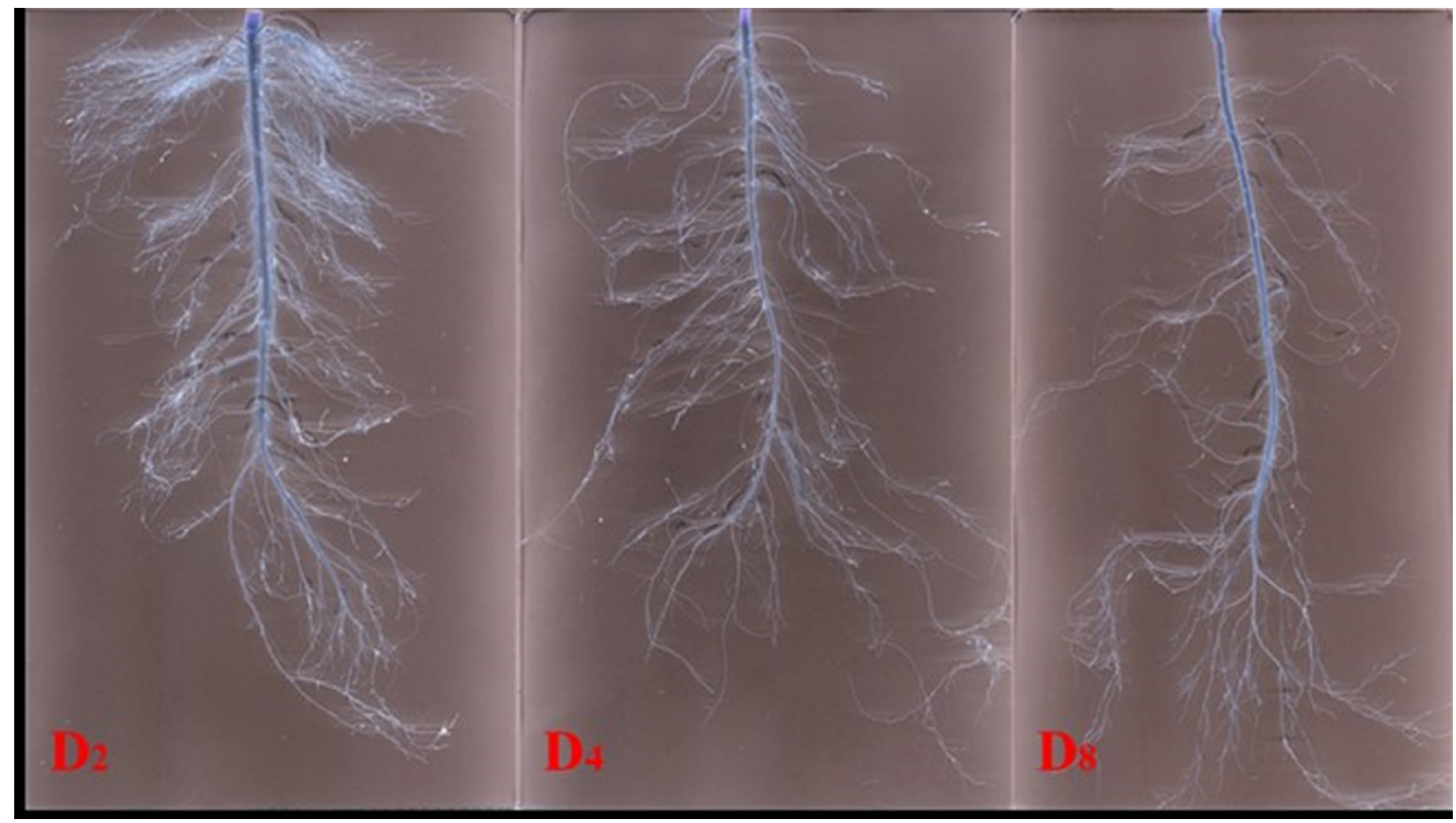




\section{Figure 3}

Semi-lethal temperatures of alfalfa cultivars crowns under different simulated rainfall events.

Mean values $(n=18) \pm$ standard errors of the mean are shown. Different capital letters and lowercase letters indicate a significant difference between three simulated rainfall events and cultivars at the same phase at 0.01 and 0.05 level respectively; ${ }^{* *}$ indicates that the same treatment had a significant difference in the two phases at 0.01 level.
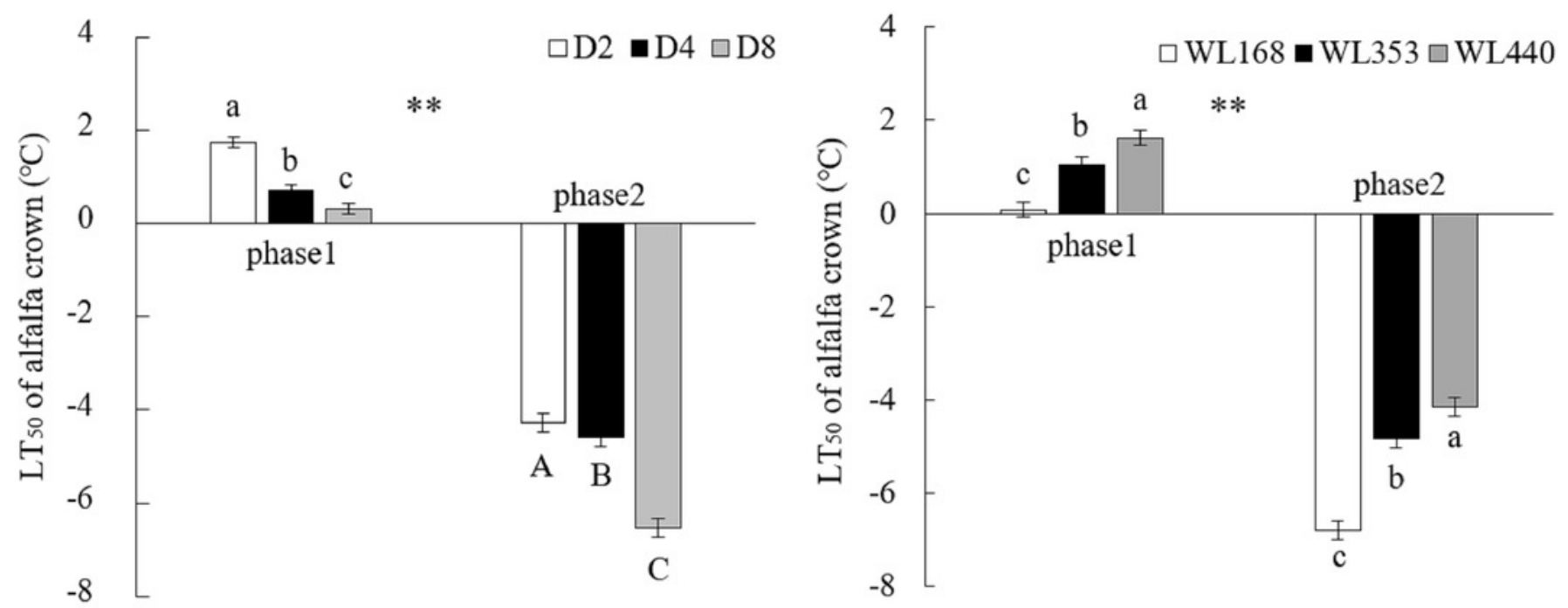


\section{Figure 4}

Principal component analysis of 10 variables and the correlations among variables and $L T_{50}$.

Each arrow represents the eigenvector corresponding to an individual variable. Different colors denote different SRE and shapes refer to cultivars. AGB, above-ground biomass; BGB, below-ground biomass; PRL, primary root length; $L R L$, lateral root length; $C D$, crown diameter; RSA, root surface area; RV, root volume; RF, root forks; TI, topological index; FD, fractal dimensions. 


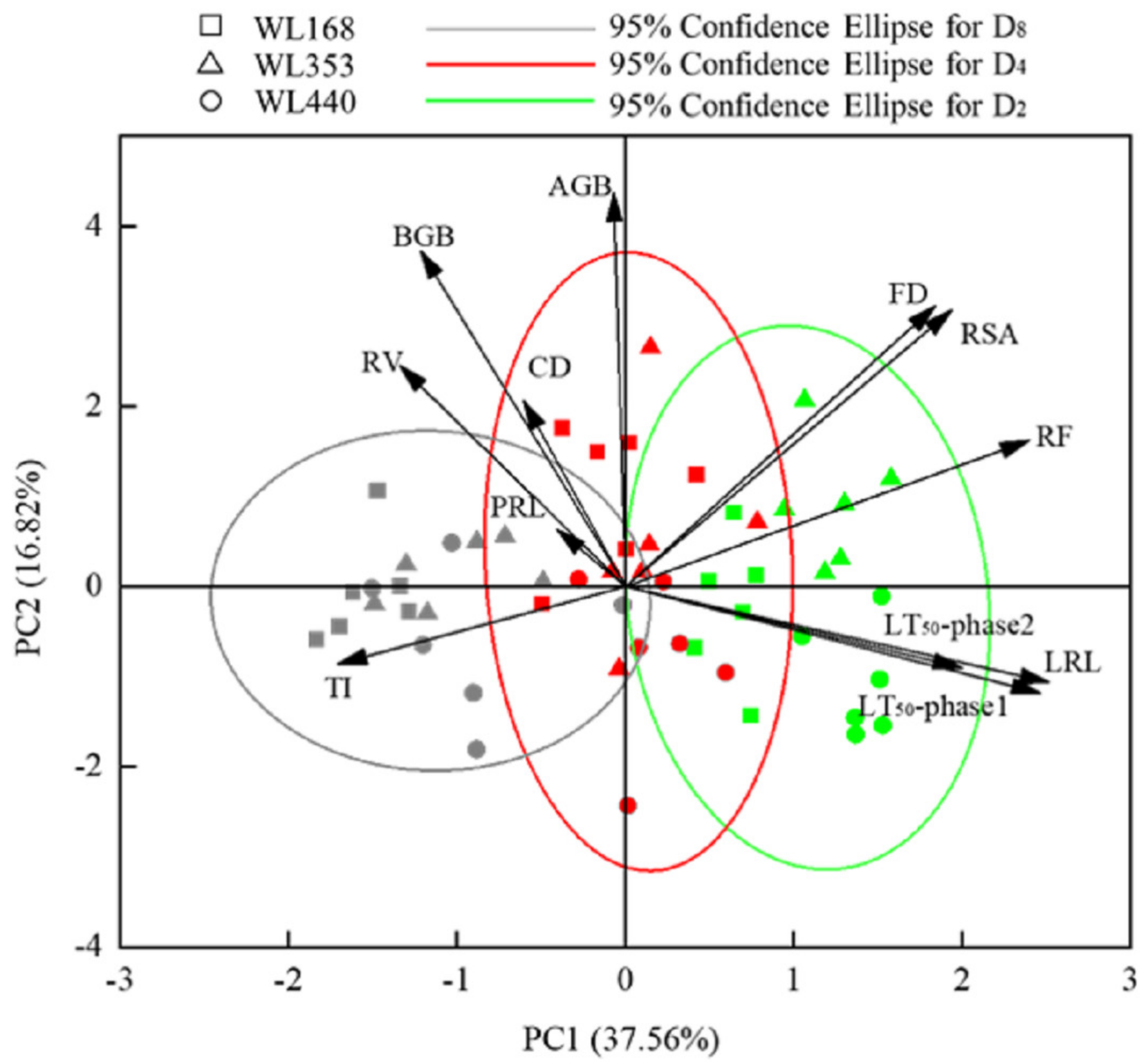




\section{Figure 5}

Malondialdehyde content under various simulated rainfall events for the three cultivars in the two phases.

Mean values $(n=18) \pm$ standard errors of the mean are shown. Different capital letters and lowercase letters indicate a significant difference between three simulated rainfall events and cultivars at the same phase at 0.01 and 0.05 level respectively.
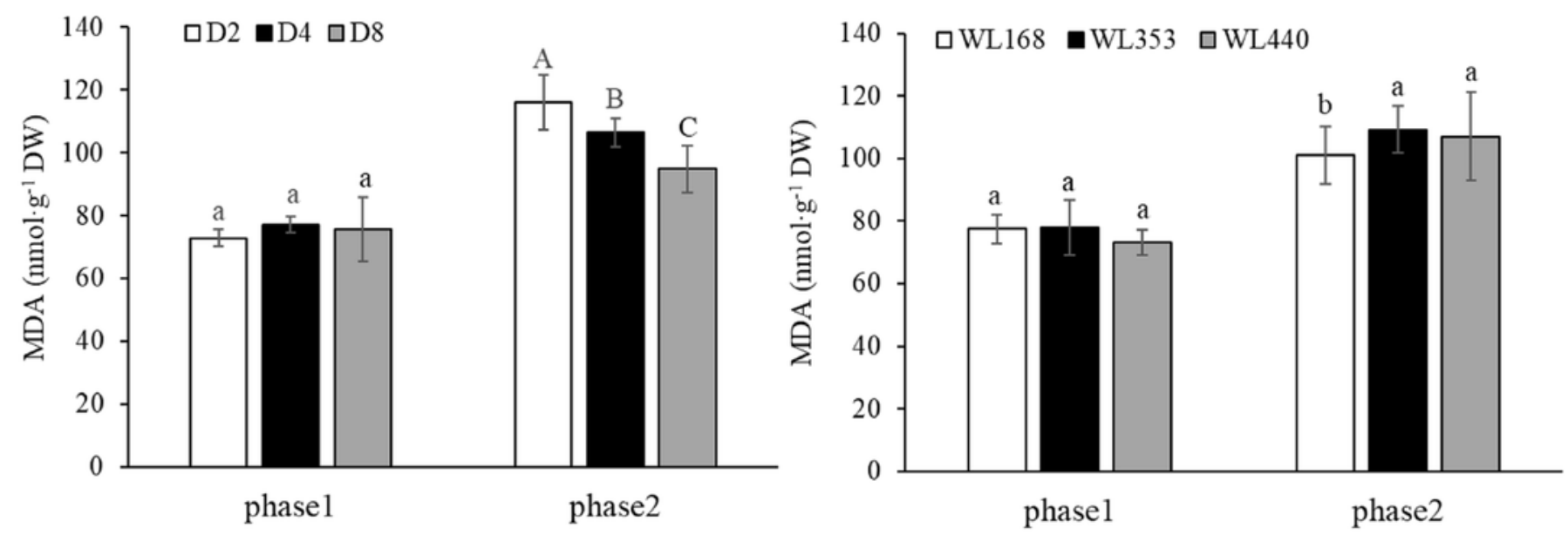
Figure 6

Proline content under various simulated rainfall events for the three cultivars in the two phases.

Mean values $(n=18) \pm$ standard errors of the mean are shown. Different capital letters indicate a significant difference between three simulated rainfall events at the same phase at 0.01 level.
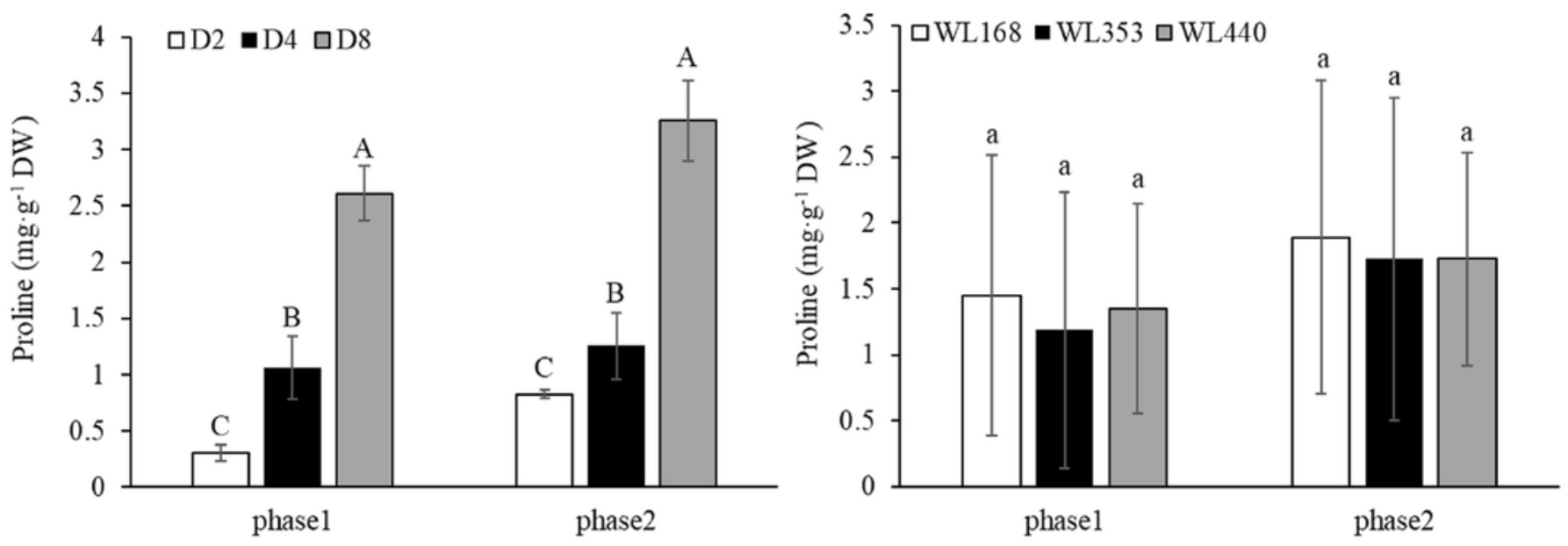


\section{Figure 7}

Soluble sugar content under various simulated rainfall events and for the three cultivars.

Mean values $(n=18) \pm$ standard errors of the mean are shown. Different capital letters indicate a significant difference between the three rainfall events at the same phase at 0.01 level.
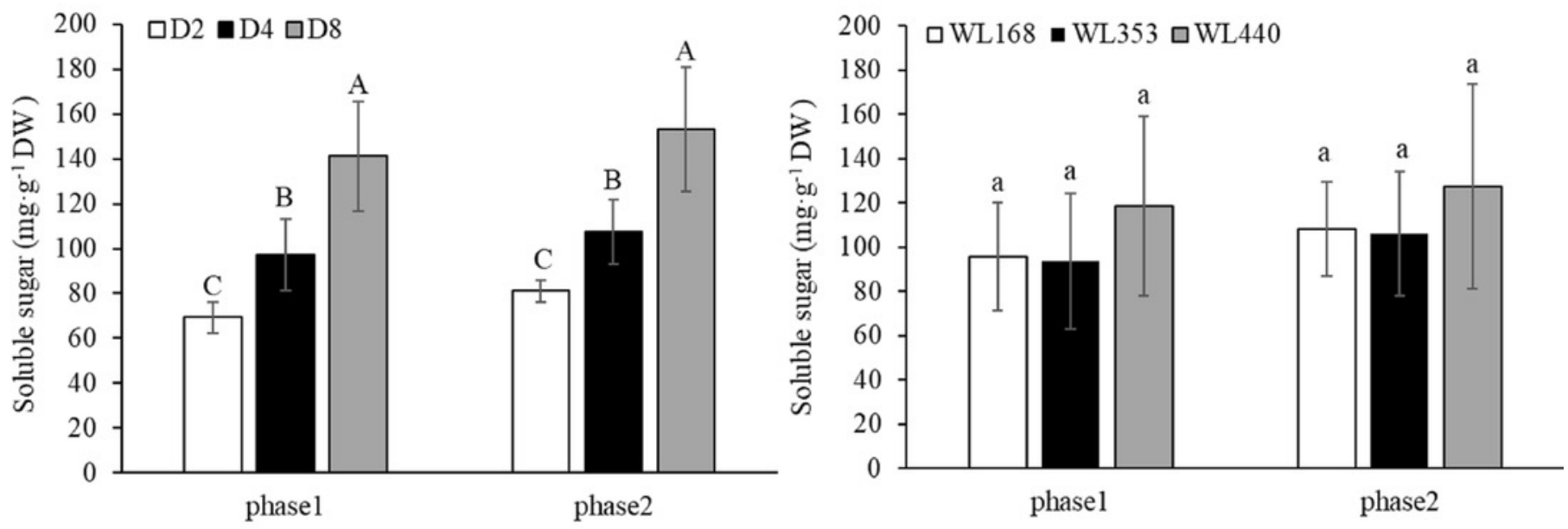
Figure 8

Starch content under various simulated rainfall events for the three cultivars.

Mean values $(n=18) \pm$ standard errors of the mean are shown. Different lowercase letters indicate a significant difference between the three rainfall events at the same phase at 0.05 level.
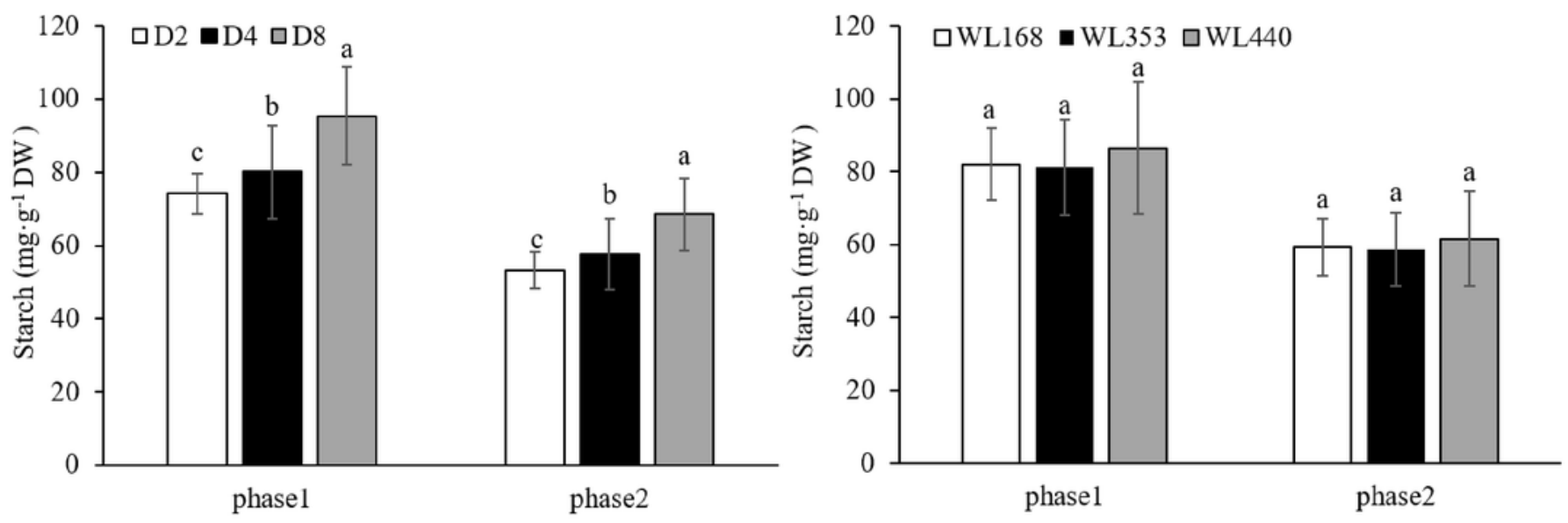